\title{
Pacific plate slab pull and intraplate deformation in the early Cenozoic
}

\author{
N. P. Butterworth ${ }^{1}$, R. D. Müller ${ }^{1}$, L. Quevedo ${ }^{1}$, J. M. O'Connor ${ }^{2}$, K. Hoernle ${ }^{3}$, and G. Morra ${ }^{4}$ \\ ${ }^{1}$ EarthByte Group, School of Geosciences, The University of Sydney, New South Wales, 2006, Australia \\ ${ }^{2}$ GeoZentrum Nordbayern, Erlangen and Alfred Wegener Institute for Polar and Marine Research, Bremerhaven, Germany \\ ${ }^{3}$ GEOMAR Helmholtz Centre for Ocean Research Kiel, Germany \\ ${ }^{4}$ Department of Physics and School of Geosciences, University of Louisiana at Lafayette, 70504, LA, USA
}

Correspondence to: N. P. Butterworth (nathaniel.butterworth@sydney.edu.au)

Received: 22 December 2013 - Published in Solid Earth Discuss.: 14 January 2014

Revised: 4 June 2014 - Accepted: 10 June 2014 - Published: 6 August 2014

\begin{abstract}
Large tectonic plates are known to be susceptible to internal deformation, leading to a range of phenomena including intraplate volcanism. However, the space and time dependence of intraplate deformation and its relationship with changing plate boundary configurations, subducting slab geometries, and absolute plate motion is poorly understood. We utilise a buoyancy-driven Stokes flow solver, BEM-Earth, to investigate the contribution of subducting slabs through time on Pacific plate motion and plate-scale deformation, and how this is linked to intraplate volcanism. We produce a series of geodynamic models from 62 to $42 \mathrm{Ma}$ in which the plates are driven by the attached subducting slabs and mantle drag/suction forces. We compare our modelled intraplate deformation history with those types of intraplate volcanism that lack a clear age progression. Our models suggest that changes in Cenozoic subduction zone topology caused intraplate deformation to trigger volcanism along several linear seafloor structures, mostly by reactivation of existing seamount chains, but occasionally creating new volcanic chains on crust weakened by fracture zones and extinct ridges. Around $55 \mathrm{Ma}$, subduction of the PacificIzanagi ridge reconfigured the major tectonic forces acting on the plate by replacing ridge push with slab pull along its northwestern perimeter, causing lithospheric extension along pre-existing weaknesses. Large-scale deformation observed in the models coincides with the seamount chains of Hawaii, Louisville, Tokelau and Gilbert during our modelled time period of 62 to $42 \mathrm{Ma}$. We suggest that extensional stresses between 72 and $52 \mathrm{Ma}$ are the likely cause of large parts of the formation of the Gilbert chain and that localised exten-
\end{abstract}

sion between 62 and 42 Ma could cause late-stage volcanism along the Musicians volcanic ridges. Our models demonstrate that early Cenozoic changes in Pacific plate driving forces only cause relatively minor changes in Pacific absolute plate motion directions, and cannot be responsible for the Hawaiian-Emperor bend (HEB), confirming previous interpretations that the $47 \mathrm{Ma} \mathrm{HEB}$ does not primarily reflect an absolute plate motion event.

\section{Introduction}

The origin of intraplate volcanism without age progression and far away from plate boundaries is poorly understood (Lee and Grand, 2012; Koppers, 2011). Intraplate volcanism can be viewed as being due to hotspots within tectonic plates, which may be caused by a range of processes including mantle plumes, small-scale convection, or lithospheric extension of plates (Ito and van Keken, 2007). In an effort to categorise these phenomena Courtillot et al. (2003) distinguished three categories of hotspots. The first is the classic WilsonMorgan type mantle plume (Morgan, 1971; Wilson, 1963), a thermal anomaly rising through the mantle due to the density difference between the core-mantle boundary and the surface. These are often long-lived and have a relatively stable source location. The second type is similar, but originates from the bottom of the transition zone, associated with superswells (Koppers et al., 2003; Romanowicz and Gung, 2002), and is comparatively short-lived. The third type (Liu and Stegman, 2012; Ito and van Keken, 2007; Hirano et al., 
2006; Koppers et al., 2003) is the most broadly classified hotspot, potentially caused by many factors, and the use of the term hotspot to describe this type of volcanism can be a misnomer. The melting anomaly may not be necessarily hot (Bonatti, 1990) and may not be a singular spot (Sandwell and Fialko, 2004). It has been suggested (Ballmer et al., 2013; Conrad et al., 2011) that shear mantle flow within the asthenosphere mostly explains this type of intraplate volcanism. However, lithospheric extension driven by plate boundary forces, plate motion, and small-scale convection may be causing intraplate volcanism as well (Ballmer et al., 2009; Koppers et al., 2003; Sandwell et al., 1995). Lithospheric cracking due to plate flexure (Hirano et al., 2006) and thermal contraction (Sandwell and Fialko, 2004) is also a possible contributor to surface volcanics. The cracking hypothesis presumes pre-existing partial melt below the surface that may be erupted when stress is applied (Ballmer et al., 2009; Hieronymus and Bercovici, 2000). Intraplate magmatism may occur in conjunction with classic hotspot volcanism, and may be associated with highly strained areas overlapping preexisting zones of weakness (Davis et al., 2002; Staudigel et al., 1991) or may create new weak zones that give rise to volcanism. Most intraplate volcanism occurs along preexisting tectonic fabric or around highly stressed lithosphere (Clouard and Gerbault, 2008a).

Here we investigate how intraplate deformation in the oceanic lithosphere may be caused by subduction-driven plate dynamics, how the stress state of the lithosphere might contribute to the occurrence and timing of volcanic melting anomalies, and to what extent intraplate volcanism may leave the lithosphere more susceptible to the passage of future melts (Hillier, 2007), focusing on the Pacific plate evolution in the early Cenozoic. This time period captures a major tectonic plate reorganisation seen in several oceanic regions between 53 and 50 Ma (Cande and Stegman, 2011; Whittaker et al., 2007) during a period of heterogeneous plate tessellation (Morra et al., 2013) whereby the ratio of large to small plates is low. Large plate accelerations have been shown to lead to increased volcanic flux (Hieronymus and Bercovici, 2000; Anderson, 1994); therefore the early Cenozoic is a good candidate for a relatively active volcanic period. A good example for such volcanism is the Cenozoic diffuse alkaline magmatic province (DAMP), which formed in the southwest Pacific after $50 \mathrm{Ma}$ (Finn et al., 2005). We analyse changes in plate motion around the Pacific Ocean basin by considering slab-pull and mantle drag/suction forces and compare the results with absolute plate reconstructions (Seton et al., 2012; Doubrovine et al., 2012; Chandler et al., 2012; Wessel and Kroenke, 2008) and the occurrence of intraplate volcanics (e.g. Clouard and Bonneville, 2005).

\section{Model setup}

We apply a novel workflow utilising a Stokes flow solver, BEM-Earth (Quevedo et al., 2012a; Butterworth et al., 2012; Morra et al., 2012, 2007), to analyse the coupled platemantle dynamics in the Late Cretaceous and early Cenozoic. Our model is driven by upper mantle slab-pull buoyancy forces (Faccenna et al., 2012) and by induced slabsuction from the down-going plates as described in Conrad and Lithgow-Bertelloni (2004, 2002). A BEM-Earth simulation requires a set of rheological isosurfaces (here represented by the lithospheric plates, the core and the external Earth surface). Each isosurface bounds a homogeneous region characterised by an effective density and viscosity. In our models these are defined by the surface location of the Pacific, Izanagi, Farallon, and Kula plates and their attached lithosphere and subducting slabs (Fig. 1).

The location of the plates and subducting slabs, used as an initial model starting condition, are determined using tectonic reconstructions from Seton et al. (2012) as implemented in the GPlates software (Boyden et al., 2011). We use reconstructed topologically closed plate boundaries through time, along with modelled plate lithospheric thickness to produce a three-dimensional representation of the Pacific plate through time. Oceanic lithosphere thickness is derived from the reconstruction model along with oceanic palaeo-age grids with a $1^{\circ} \times 1^{\circ}$ resolution (Müller et al., 2013). Ages are input into a half-space cooling model to determine plate thickness, as used previously in BEM-Earth (Morra et al., 2012, Appendix B).

We seek to simulate the effect of slab pull and slab suction on the Pacific plate. For this we assume that the convergence history between a subducting and an overriding plate is related to the amount of slab material contributing to the pull force. We utilise 10 million years of subduction history, from plate kinematic reconstructions, to provide an estimate of slab material that drives the slab-pull force in BEM-Earth. A 10 million year interval reflects the approximate time for a slab to subduct to the lower mantle and thus estimates the portion of the slab in the upper mantle contributing to the slab pull (Conrad and Lithgow-Bertelloni, 2002, 2004; Billen, 2008). To determine initially subducted slab morphology we advect subducting plates into the mantle using surface plate kinematics based on published plate rotations (Seton et al., 2012) starting $10 \mathrm{Myr}$ before the geodynamic model starting time. The absolute and convergent velocities are determined for each point along the reconstructed subduction zone for each time period (Quevedo et al., 2012b). Absolute motion of the trench defines the surface rotation of the slab's position (horizontal component of slab dip) and the convergence rate between the subducting and overriding plate define the upper mantle slab sinking rate (vertical component of slab dip). The initial dip of the slab does not affect the BEM-Earth simulation (Morra et al., 2012), but rather having the correct amount of upper mantle slab material (Quevedo et al., 2012b; 


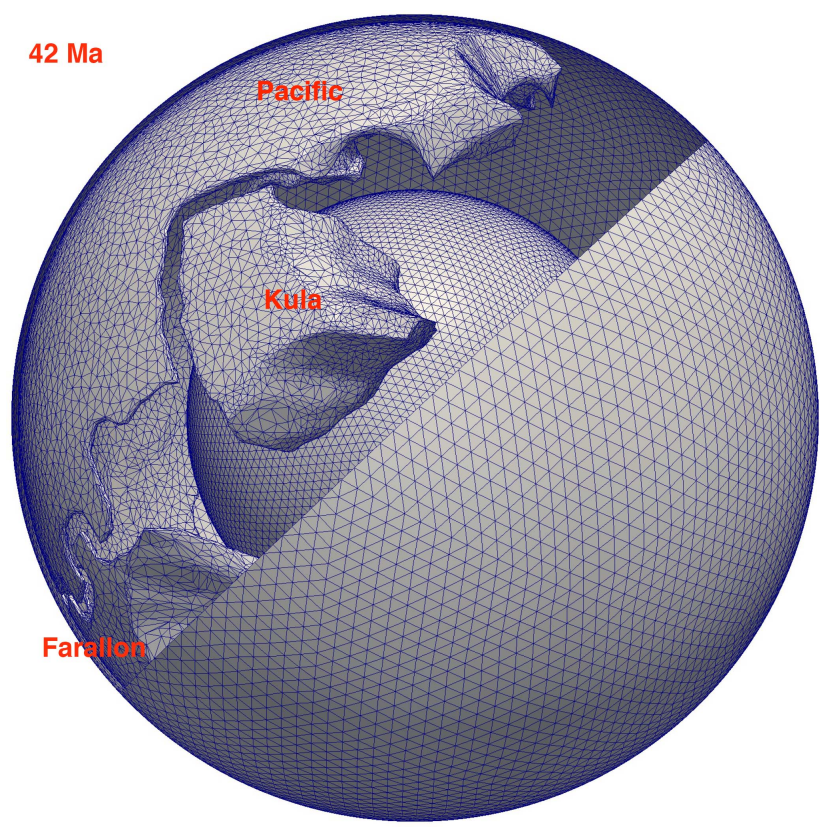

Figure 1. The initial starting model used for input into BEM-Earth. Each isosurface bounds a region of discrete viscosity and density as described in Table 1. The external Earth surface has been peeled back to show the other core and plate isosurfaces, with the view centred near the North Pole. The modelled plates, here at $42 \mathrm{Ma}$, are the Kula, Farallon and Pacific. The blue mesh is indicative of model resolution and shows the panels that are free to deform.

Billen, 2008; Schellart, 2004) is important for simulating driving forces. Nevertheless, resulting dips of slabs from a present-day model run are comparable with Slab1.0 (Hayes et al., 2012, Appendix A). At each reconstructed point, we calculate the volume of the slab driving the model, as the convergence rate times the lithospheric thickness added up in $1 \mathrm{Myr}$ time steps for the $10 \mathrm{Myr}$ prior to the model start time. In summary, the slab structure is constructed from the relative motion of the plates in the plate reconstructions for the $10 \mathrm{Myr}$ prior to the model being run. For example, the $52 \mathrm{Ma}$ model uses subduction history between 62 and $52 \mathrm{Ma}$ to generate the slab structure driving this geodynamic model.

The resulting modelled plate consists of a mantle viscosity and density structure that is post-processed to ensure smooth non-overlapping 3-D surfaces. This is required to maintain a consistent isostatic equilibrium between the model isosurfaces (Butterworth et al., 2012; Morra et al., 2012). Rheology of the plate is defined by an isosurface bounding a region of homogeneous density and viscosity (as described in Table 1). We approximate the fluid dynamics of subduction by considering the mantle and the lithosphere as regions of homogeneous density and viscosity, disregarding other chemical and rheological inhomogeneities. We assume a simple temperature-independent rheology for such multiphase flow, and model only the fundamental forces controlling the process (Quevedo et al., 2012a), which we take to be: the buoy-
Table 1. Reference model parameters

\begin{tabular}{lllll}
\hline Parameter & $\begin{array}{l}\text { Sym- } \\
\text { bol }\end{array}$ & $\begin{array}{l}\text { Non- } \\
\text { dimensional } \\
\text { value }\end{array}$ & $\begin{array}{l}\text { Natural } \\
\text { value }\end{array}$ & Units \\
\hline Earth radius & $r_{\mathrm{E}}$ & 1 & 6371 & $\mathrm{~km}$ \\
Mantle viscosity & $\eta_{\mathrm{m}}$ & 1 & $10^{21}$ & $\mathrm{~Pa} \mathrm{~s}$ \\
Mantle density & $\rho_{\mathrm{m}}$ & 50 & 3300 & $\mathrm{~kg} \mathrm{~m}^{-3}$ \\
Slab viscosity & $\eta_{\mathrm{s}}$ & $100 \times \eta_{\mathrm{m}}$ & $10^{23}$ & $\mathrm{~Pa} \mathrm{~s}^{-3}$ \\
Slab density & $\rho_{\mathrm{s}}$ & 80 & 3330 & $\mathrm{~kg} \mathrm{~m}^{-3}$ \\
\hline
\end{tabular}

ancy resulting from the different densities between the flow phases; the viscous drag that might hamper or assist plate motion; and the viscous resistance to bending and stretching. The simplified rheology structure is free to deform, and is a simple, yet fair representation for modelling plate-scale lithospheric processes (Capitanio et al., 2010; Li and Ribe, 2012). Each subducting plate is embedded in a homogeneous mantle fluid surrounded by an adaptive external surface. We use a mantle without viscosity layering to simplify our model; however, the role of mantle layering would influence the trench and slab morphology as well as the plateness of a large plate like the Pacific (Morra et al., 2012). Viscosity layering of the mantle would decrease the importance of slab suction relative to slab pull but is probably not sufficient to significantly affect plate motions (Conrad and LithgowBertelloni, 2004). The viscosity contrast between each isosurface is fixed for the simulation, thus thermal effects are not considered in the model.

Resolution of the model is determined by the size of triangular elements (panels) constituting each rheological isosurface, which is $\sim 50 \mathrm{~km}$. Evolution of the model is driven by the negative buoyancy of the already subducted lithosphere. As no lithosphere is being replenished at the midocean ridges, we only run the model for a few million years at a time to obtain the intraplate stress state of the lithosphere, indicating areas of likely deformation, and velocities of the plates. The tapered lithospheric thickness at the ridges of the model isosurfaces prompts a ridge-push force to contribute to plate motion; however, the force is diminished by a "surface contact layer" (Butterworth et al., 2012; Morra et al., 2012). The contact layer keeps the plates in isostatic equilibrium by preventing the slab from detaching from the external Earth surface boundary and sinking vertically; rather the subducting plate advances in a more realistic fashion. There are several methods for providing this balancing buoyancy force in numerical models (Ribe, 2010; Stegman et al., 2010; Morra et al., 2007). Here we use a "lubrication layer" method, where the Earth surface boundary is described as an adaptive surface, whose dynamic behaviour is controlled partially by the distance between the model isosurfaces. The ridge-push force contributes less than $10 \%$ (Lithgow-Bertelloni and Richards, 1998) to forces driving 
plate motions - in BEM-Earth models we find that this force contributes less than $5 \%$ due to the contact layer overwhelming the interaction (Butterworth et al., 2012).

\subsection{Plate deformation}

We extend the work of Clouard and Gerbault (2008a) into a 3-D spherical domain, where we examine intraplate deformation driven by plate-scale tectonics and its relationship to volcanism. However, we use a dynamic simulation with no external velocity forcing. The natural strains, $\epsilon$, are calculated for each model panel through time using $\epsilon=\frac{\ell-L}{L}$, where $L$ and $\ell$ are the original and final lengths of model panels respectively. Principal-axis stresses are then computed from the natural strains and strain rosette gauge transformation tensors. The second deviatoric stress invariant, which is an effective or equivalent stress that can be used as an indication for likely regions of deformation (Gueydan et al., 2008), is defined in three dimensions as $\sigma_{\mathrm{e}}=$ $\frac{1}{\sqrt{2}} \sqrt{\left(\sigma_{1}-\sigma_{2}\right)^{2}+\left(\sigma_{2}-\sigma_{3}\right)^{2}+\left(\sigma_{3}-\sigma_{1}\right)^{2}}$, where $\sigma$ is the principal stress in each of the three axes (Boresi and Schmidt, 2003). When the second deviatoric stress invariant reaches a critical value (known as the von Mises yield criterion) yielding of the plate will occur (possibly expressed through volcanism in the geological record). This "likelihood" for a plate to fracture increases if an area of high $\sigma_{\mathrm{e}}$ values has preexisting weakness or is under stress from some other mechanism.

The plate with a simplified rheology is free to deform due to forces driving the natural evolution and transmission of stresses in the plate. Areas of likely deformation are determined over a phase of steady model evolution after a period of initialisation. This delay in measurement allows the model to equilibrate. However, results are found to be similar when $\sigma_{\mathrm{e}}$ is measured early or later in the simulation. Intraplate stresses are much higher in our model than in reality, since we do not use a highly viscous plate core or model the plastic deformations that play a role in real plates. The constitutive relationship of the material that we use for the plate can be regarded as unrealistic, but models of the semi-rigid rheology of the plates as part of a global model have so far only been applied to present-day plate motions (e.g. Stadler et al., 2010), never to sequences of models for the past. Preexisting zones of weakness (e.g. fracture zones) likely act as conduits for melting anomalies (Davis et al., 2002), but platescale stresses due to subduction processes may provide the deformation required to promote volcanics. Volcanism is not expressed in the models, but we use ${ }^{40} \mathrm{Ar} /{ }^{39} \mathrm{Ar}$ dates for the relatively few samples available from seafloor volcanism edifices, to see whether a link can be established in some places between areas likely to deform due to subduction forcing and spatio-temporal localisation of hotspot melting anomalies.

\section{Model results}

We run four subduction-driven models which start with surface reconstructions at $62,52,47$ and $42 \mathrm{Ma}$ and include the previous 10 million years of subduction material for each time period as an initial condition. The resulting model deformation at the surface of the plate, inferred from the second deviatoric stress invariant, is correlated with age-dated volcanic structures, and the model kinematics are compared with alternative plate model reconstructions. The modelled second deviatoric stress invariant produces similar structure on the underside of the plate and the surface and we report the surface values. Slab pull due to slab material mechanically attached to subducting plates and the resulting slab suction induced by these down-going slabs are the only significant model-driving forces (Morra et al., 2012; Butterworth et al., 2012). For each model and kinematic reconstruction, we report the mean direction of motion of the Pacific. Although the rigidity (the plateness) of the geodynamic modelled plate is low, we compare plate motions with the rigid kinematic models, as a simple test for how well we are reproducing absolute plate motions. Our models cannot capture changes over time periods in between model runs, but rather represent the average motion change between modelled intervals.

\subsection{Ma reconstruction}

The reconstructed Pacific plate at $62 \mathrm{Ma}$ (Fig. 2) has only one subducting slab mechanically attached to it, along the East Junction subduction zone, located to the north of Australia between the Tethys and Panthalassa (Seton and Müller, 2008). At this time, the Junction slab attached to the Pacific consists of $\sim 4 \%$ of all global upper-mantle slab material (Appendix B). The subducting plates, Izanagi, Kula and Farallon, that surround the Pacific have subduction zones with over $70 \%$ of global slab material driving them. Reconstructed Pacific plate velocities from Seton et al. (2012) show the plate heading toward the northwest $\left(303^{\circ}\right)$. The Doubrovine et al. (2012) reconstructions have the Pacific moving generally toward the north $\left(15^{\circ}\right)$. The Izanagi, Kula and Farallon plates maintain the dominant subducting slabs around the Pacific. The direction of movement of the modelled Pacific $\left(287^{\circ}\right)$ is more in line with those predicted by the Seton et al. (2012) reconstructions. We observe the areas likely to deform on the plate at $62 \mathrm{Ma}$ to be contrasted across the plate with a large zone of focused high stress running from the centre of the Pacific to the northwest intersection with the Izanagi plate.

\subsection{Ma reconstruction}

Between 62 and $52 \mathrm{Ma}$ the Pacific plate model undergoes a relatively major change in its kinematics and topology (Fig. 3). The Izanagi plate is now fully subducted and its subducting slab is mechanically attached to the northwest 


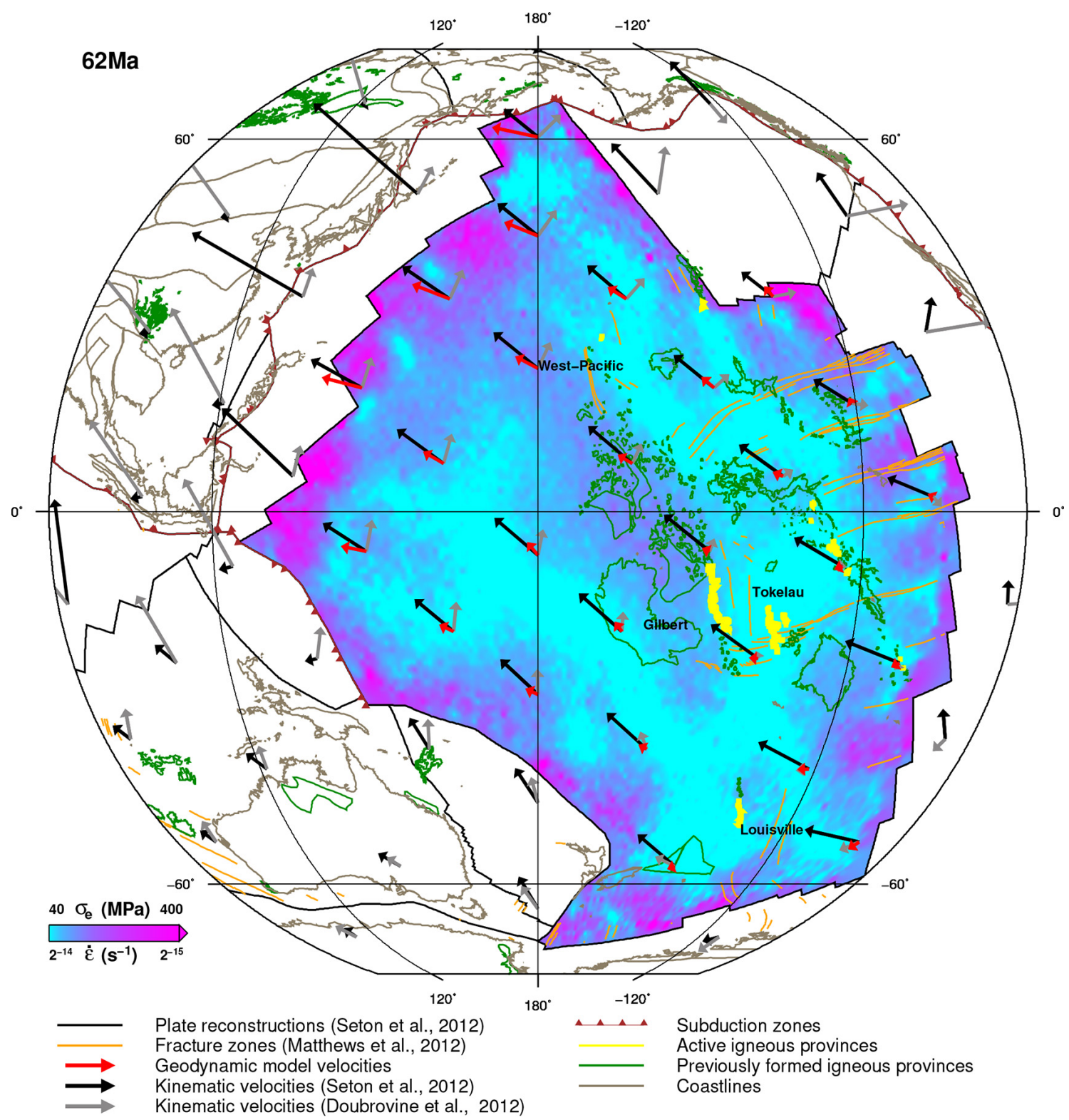

Figure 2. Pacific plate reconstruction and model output at $62 \mathrm{Ma}$. Palaeo-plate reconstructed positions (Seton et al., 2012) are outlined in black, with attached subduction zones in red. Velocities of kinematic plate reconstruction models are shown by the black (Seton et al., 2012) and grey arrows (Doubrovine et al., 2012). Our subduction-model-derived velocity vectors are shown by red arrows. The yellow features are the reconstructed positions of age-dated igneous provinces that have appeared in the $10 \mathrm{Myr}$ preceding the model (see discussion for references). Igneous structures are outlined in green. Significant locations are labelled. Orange lines are the reconstructed fracture zone locations (Matthews et al., 2011). The brown outlines represent the reconstructed positions of the present-day coastlines. The aqua to magenta logarithmic colour scale represents the second deviatoric stress invariant $\left(\sigma_{\mathrm{e}}\right)$ of our model and the strain rate $\left(\dot{\varepsilon}=\sigma_{\mathrm{e}} / 2 \eta_{s}\right)$, with aqua representing minimal potential for plate deformation and magenta representing the maximal potential for deformation at the surface of the modelled plate. The smooth, homogeneous style of deformation at the borders of divergent and passive margins is a post-processing artefact due to the interpolation of the grid of the deviatoric stress values onto the reconstructed edge of the plate boundary.

portion of the Pacific plate. The exact timing and location of Izanagi ridge subduction is not well resolved (Whittaker et al., 2007; Seton et al., 2012). In our model the Izanagi ridge subducts roughly parallel to the trench. The western flank of the Izanagi ridge flank is still contributing to the pulling force acting on the Pacific plate at $52 \mathrm{Ma}$ after ridge subduction. Previous modelling (Burkett and Billen, 2009) suggests that ridge subduction is not a pre-requisite for a loss of slab pull.
Subducting slabs attached to the Pacific plate now account for $\sim 24 \%$ of global material being subducted. The Farallon and Kula plates have down-going material accounting for $\sim 24 \%$ and $\sim 12 \%$ of global material respectively. This induces high stress just behind the subduction zone in the down-going Pacific plate. This high-stress region feeds into the same northwest trending feature seen at $62 \mathrm{Ma}$ that tapers off toward the centre of the plate. There are also smaller zones of high-stress scattered around the plate. The modelled 


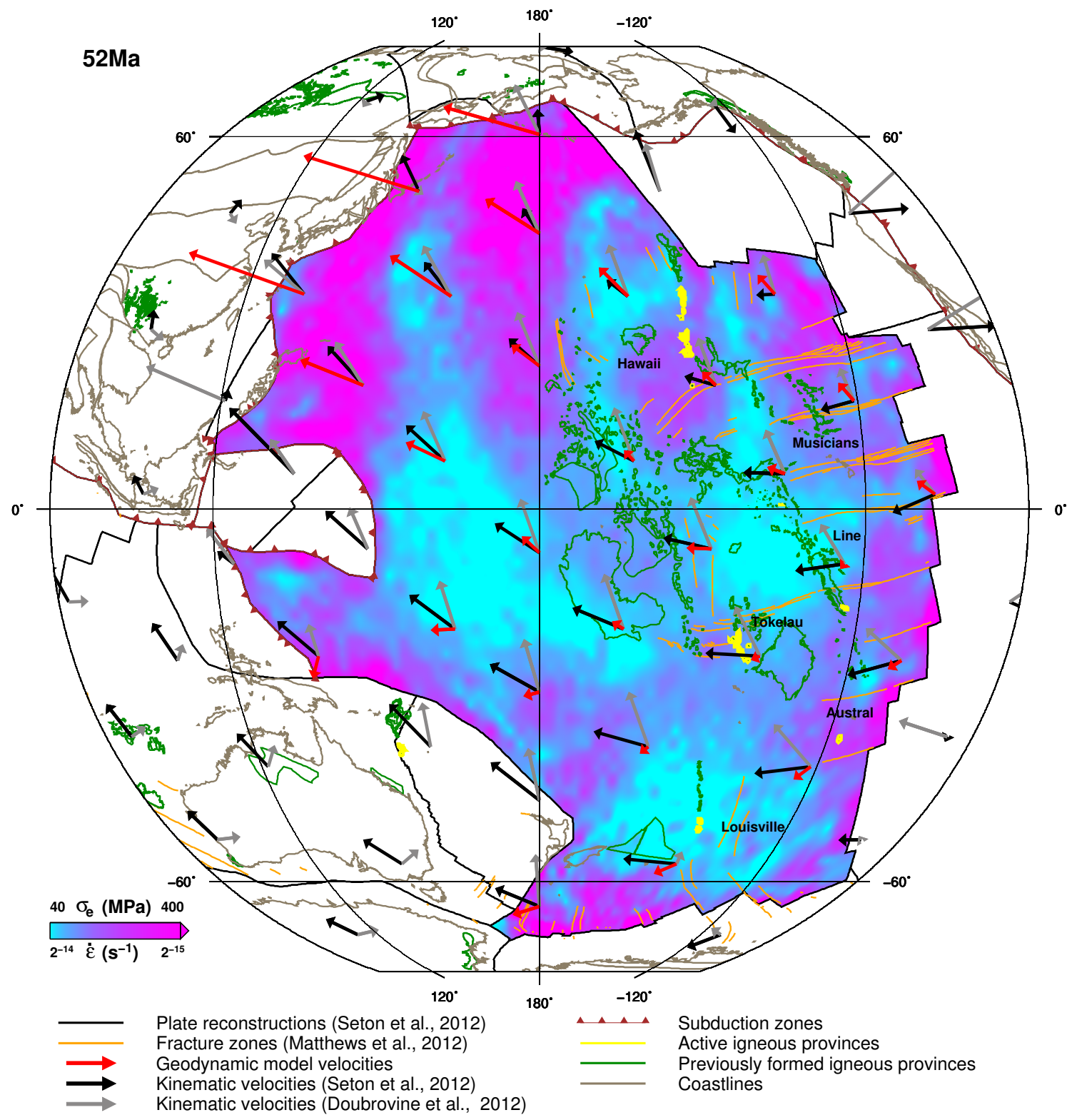

Figure 3. As Fig. 2 but for the Pacific plate reconstruction and model output at $52 \mathrm{Ma}$.

velocities show the Pacific moving westerly $\left(280^{\circ}\right)$, and rotating clockwise. As subduction is now the major driver of the Pacific plate, the model velocity vectors are more consistent with the direction of the velocities of Seton et al. (2012) $\left(293^{\circ}\right)$. In the model the velocities are exaggerated close to the subduction zone. The Doubrovine et al. (2012) velocities have increased in magnitude and show the Pacific moving more westerly $\left(337^{\circ}\right)$, similar to the Seton et al. (2012) reconstructions during this epoch. Doubrovine et al. (2012) reconstructions favour a more northward trend to our model velocities and the Seton et al. (2012) reconstructions.

\subsection{Ma reconstruction}

The Pacific plate approaches periods of rapid change in the Seton et al. (2012) reconstruction between 52 and $42 \mathrm{Ma}$. We run a model in the intervening period at $47 \mathrm{Ma}$ to capture this change. At this time (Fig. 4) the major subduction zone attached to the Pacific is only along the west and northwest region, now accounting for $\sim 15 \%$ of global slab material, topologically similar to the $52 \mathrm{Ma}$ model. The other major dynamic influences come from the Kula and Farallon plates and their attached subducting slabs, which account for $\sim 16 \%$ and $\sim 33 \%$ of global slab material respectively. The Pacific plate in our model is now moving in a predominantly westerly direction $\left(283^{\circ}\right)$ and has slowed corresponding with 


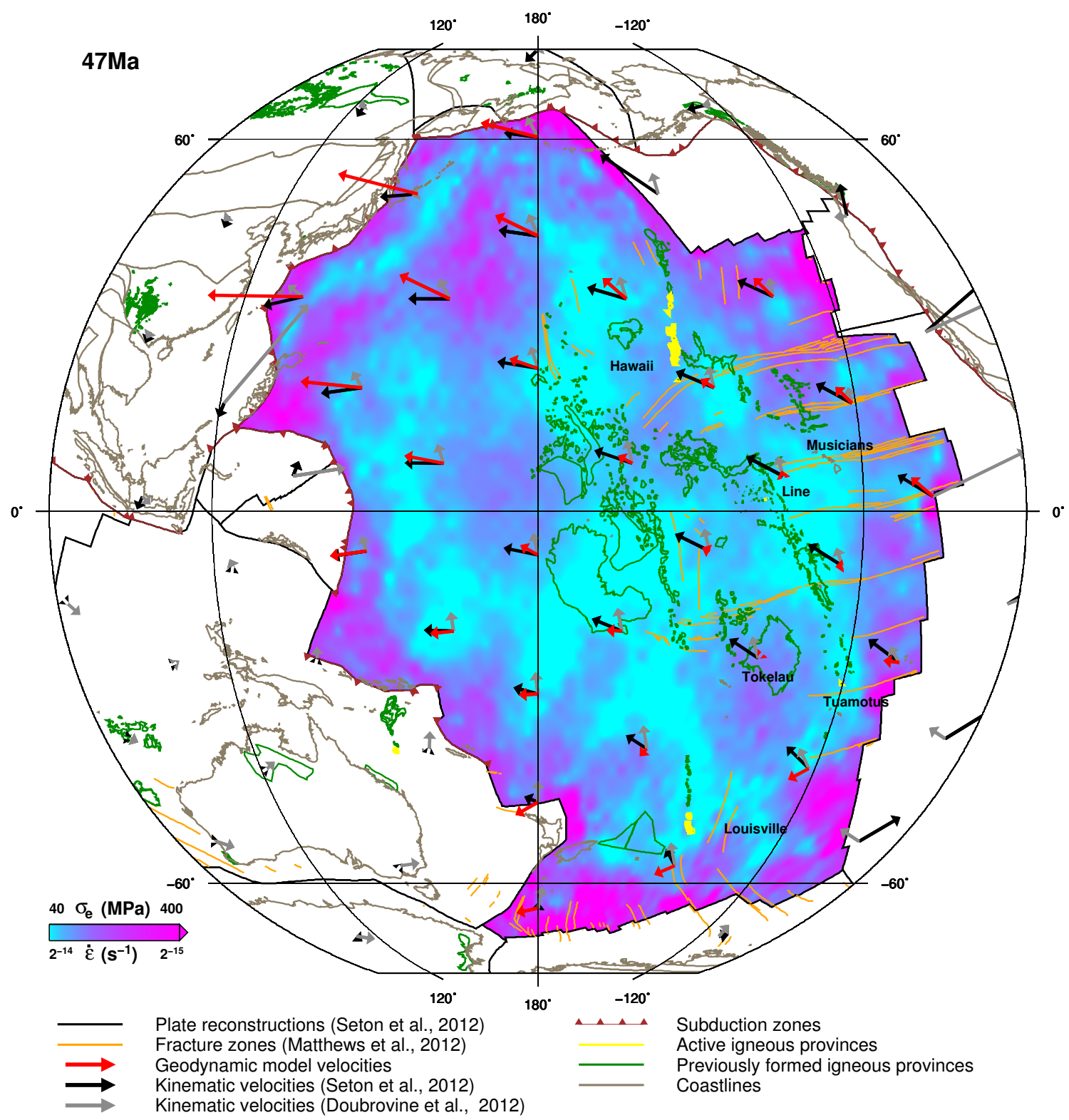

Figure 4. As Fig. 2 but for the Pacific plate reconstruction and model output at $47 \mathrm{Ma}$.

a decrease in assumed depth of initial slab material. The large subducting slab attached to the Pacific plate is the main driver of plate motion in this epoch. The model and reconstructed velocity vectors of Seton et al. (2012) $\left(288^{\circ}\right)$ agree well overall. Doubrovine et al. (2012) plate velocities trend more to the north $\left(341^{\circ}\right)$ and the magnitude has decreased significantly since $52 \mathrm{Ma}$. The stress state of the plate has similar style to the $52 \mathrm{Ma}$ model, with patches of high-stress appearing over the plate or propagating from the edges; however, the large region indicating deformation propagating from the northwest subduction zone has been greatly dissipated.

\subsection{Ma reconstruction}

The modelled Pacific at $42 \mathrm{Ma}$ (Fig. 5) is kinematically and topologically similar to the $47 \mathrm{Ma}$ model. The same subduction zones continue to drive the Pacific as from the $47 \mathrm{Ma}$ model epoch. The mean model direction $\left(288^{\circ}\right)$ has the same northwest trend as the Seton et al. (2012) reconstructed plate motion vectors $\left(294^{\circ}\right)$, whereas Doubrovine et al. (2012) reconstructions show the Pacific undergoing an absolute motion change, trending from north at $47 \mathrm{Ma}$ to now northwest $\left(310^{\circ}\right)$. The areas of high stress are maintained in similar locations to $47 \mathrm{Ma}$. 


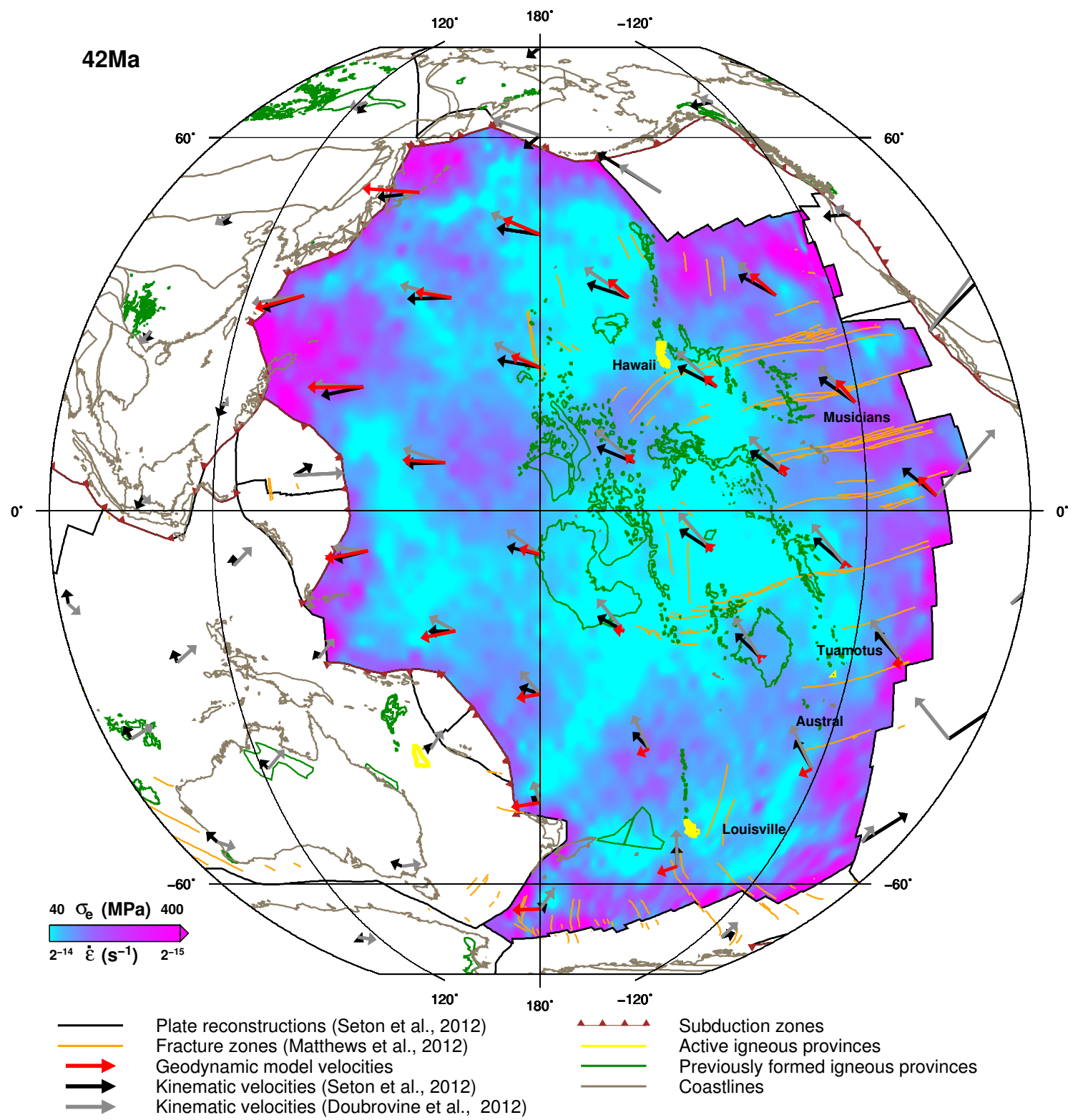

Figure 5. As Fig. 2 but for the Pacific plate reconstruction and model output at $42 \mathrm{Ma}$.

\section{Discussion}

\subsection{Kinematic vs. geodynamic model plate motions}

The plates in our geodynamic model are primarily driven by slab material pulling on a given attached plate. Contributions of induced mantle flow, expressed as a suction force, are secondary to this, but can still be appreciable, depending on the location of the slabs relative to the plates (Morra et al., 2012). The slab-suction force is driven from the slabs attached to the down-going plates, but we do not model the effect of traction that may be induced by other density heterogeneities in the mantle (Ricard et al., 1993). The role of slab-suction is most evident in the motion of the $62 \mathrm{Ma} \mathrm{Pa}-$ cific, where the plate has no major subduction zones, but continues to move towards the northwest as predicted by kinematic reconstructions (Seton et al., 2012). At times when massive subduction zones bound the Pacific plate, motion in our models is expected to better predict plate reconstructions, because the models are primarily driven by the pull of slabs mechanically attached to the down-going plate. Thus we find that the direction of motion of the Pacific plate is closer to resembling the kinematically derived plate motions of Seton et al. (2012) during these times. The geodynamic model uses non-dimensional rheological parameters; therefore renormalisation of plate velocities to Earth-like values is carried out in a post-processing step. We use the same model 
time renormalisation as Morra et al. (2010), $\eta /(\Delta \rho \cdot g \cdot r)$, where $\eta$ is the mantle viscosity, $\Delta \rho$ is the differential density between the external surface and the mantle, $g$ is gravity, and $r$ is the radius of the Earth. We find a mantle-Earth differential density of $\Delta \rho=60 \mathrm{~kg} \mathrm{~m}^{-3}$, and a mantle viscosity of $\eta=1 \times 10^{21} \mathrm{Pas}$, as listed in Table 1 , best match kinematic reconstruction velocity magnitudes.

The correspondence between the model velocities favouring Seton et al. (2012) over Doubrovine et al. (2012) derived velocities, are in part because the Doubrovine et al. (2012) plate model has been constructed to include Pacific hotspots that mimic the Hawaiian-Emperor bend (HEB). However, because this hotspot track is likely uniquely related to mantle flow, perhaps involving ridge-plume capture (Tarduno et al., 2009), we find that our subduction-driven model better fits Seton et al. (2012) (based on the hotspot moving reference frame of O'Neill et al., 2005) reconstructions. Figure 7 shows the motion paths of the fixed Hawaiian and Louisville hotspots through time relative to the Pacific plate as reconstructed by different models.

Furthermore, between 83.5 and $45 \mathrm{Ma}$ the Seton et al. (2012) and Doubrovine et al. (2012) plate motions are constrained using different plate circuits. Between 50-70 Ma there is a large transition in the absolute plate motion of the Doubrovine et al. (2012) model attributed to the fast motion of the Indian plate. This could be a point of model velocity mismatch, as our models do not include plates far from the Pacific.

To constrain the reliability of our modelled plate motions we compute best-fit Euler poles from our model velocity fields using the Matlab Euler Pole Calculator (EPC) from Goudarzi et al. (2014) (averaged from the motion of the entire non-rigid Pacific plate). We use the resulting stage poles (Table 2) to compute finite reconstruction poles (Table 3 ) by adding our model stage rotations to the 42 Ma finite rotation for the absolute motion of the Pacific plate from Seton et al. (2012) as our model does not provide rotations for times after $42 \mathrm{Ma}$ (Fig. 6). We compare the resulting model pole path with those of four published plate reconstructions (Fig. 6). For the time period modelled here (62-42 Ma) Wessel and Kroenke (2008) determine plate motions by assuming fixed hotspots in the Pacific. Alternatively Doubrovine et al. (2012) applies a moving Pacific, Atlantic and Indian hotspot model, with rotations of the Pacific linked through a plate circuit to the absolute reference frame. Euler poles determined from Chandler et al. (2012) and Wessel and Kroenke (2008) are strikingly similar in absolute motion through time as both models rely on a Pacific hotspot reference frame. They deviate from each other after $47 \mathrm{Ma}$ as Chandler et al. (2012) interprets the rapid change in Pacific plate motion expressed in the HEB as being due to a slowdown in drift of the Hawaiian plume.

Each of the four published plate reconstruction models implies some change in Pacific plate motion between 62 and $52 \mathrm{Ma}$. The disparity of the Wessel and Kroenke (2008) Eu-
Table 2. Stage rotations for absolute Pacific plate motion from the geodynamic model.

\begin{tabular}{llll}
\hline Time period & Latitude & Longitude & Angle \\
\hline $47-42 \mathrm{Ma}$ & 69.4049 & -24.2841 & -1.8404 \\
$52-47 \mathrm{Ma}$ & 65.3369 & -30.538 & -2.0658 \\
$62-52 \mathrm{Ma}$ & 60.2093 & -47.641 & -4.9922 \\
$72-62 \mathrm{Ma}$ & 63.3748 & -52.2041 & -2.6762 \\
\hline
\end{tabular}

Table 3. Finite poles of rotation for the geodynamic model.

\begin{tabular}{lccc}
\hline Time & Latitude & Longitude & Angle \\
\hline $42 \mathrm{Ma}$ & 65.9747 & 314.4962 & 31.3938 \\
$47 \mathrm{Ma}$ & 66.3074 & 312.0884 & 33.6642 \\
$52 \mathrm{Ma}$ & 69.5168 & 298.9913 & 37.9722 \\
$62 \mathrm{Ma}$ & 63.8622 & 299.4621 & 46.4814 \\
\hline
\end{tabular}

ler poles from the other models (Fig. 6) highlights the impact of including fixed Pacific hotspots in plate reconstructions without considering differential hotspot motion or seamounts offset from hotspot locations. Synthetic hotspot tracks for all models, except for the Wessel and Kroenke (2008) model, which fits the geometry of the Hawaii-Emperor and Louisville chains very closely, are shown on Fig. 7. The pole path associated with our dynamically modelled Pacific displays a kink at $52 \mathrm{Ma}$ (Fig. 6). However, this kink is expressed only as a very subtle variation in direction of Pacific plate motion around the HEB and therefore mismatches the Emperor chain severely (Fig. 7). In addition the Louisville chain is also not well matched by our model and in both cases the mismatches are similar to those of the Seton et al. (2012) model. Our dynamically subduction-driven motions of the Pacific plate are agnostic of mantle plumes and plume drift, as they are purely reliant on a given set of plate boundary topologies and reconstructions, as the plate model used determines the amount and location of slab material in the upper mantle as initial condition for our geodynamic models. The overall good correspondence between the absolute plate velocities from Seton et al. (2012) and our slab-driven model provides the insight that a combined relative/absolute plate motion model built without relying on Pacific hotspot tracks, as is the case for the Seton et al. (2012) model, and particularly not the Hawaiian-Emperor chain, predicts geodynamically plausible absolute Pacific plate velocities. This is consistent with the view that the HEB reflects the slowdown of the drift of the Hawaiian plume (Tarduno, 2007; Tarduno et al., 2009) with a change in absolute (or relative) plate motion playing a minor, ancillary role. This explains why subduction-driven plate models cannot be used to predict tracks for hotspots which have not been stationary during the model time interval. This is clearly the case for the Hawaii hotspot during Emperor chain formation (Tarduno, 2007; Tarduno et al., 2009): for the time interval of interest 


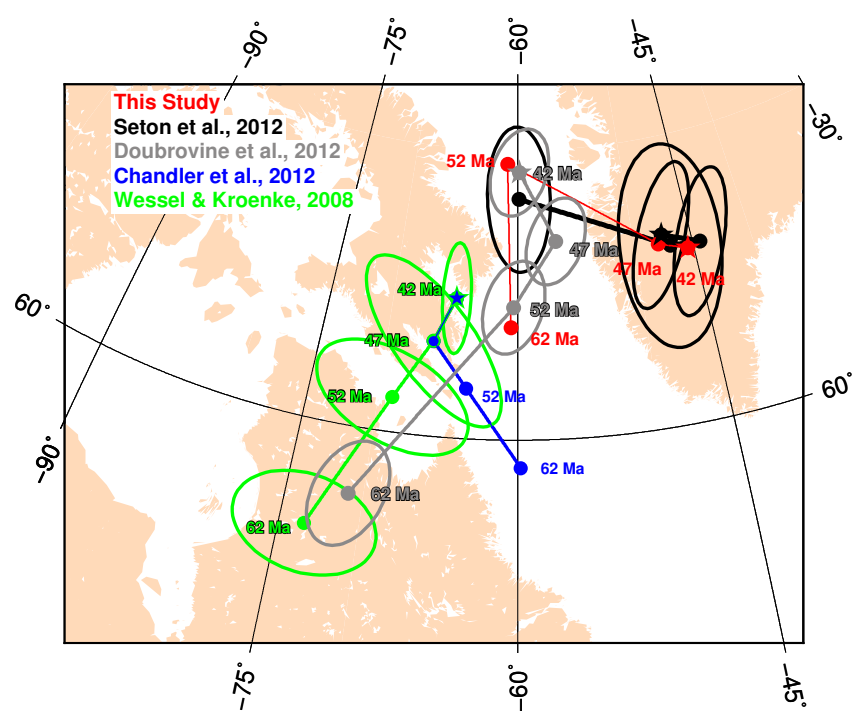

Figure 6. Finite reconstruction pole locations for the absolute motion of the Pacific plate at each of the model times. The five different absolute reference frames are coloured as in the legend. Stars represent the $42 \mathrm{Ma}$ Euler poles and progressive points are the 47, 52 and $62 \mathrm{Ma}$ poles. Present day continents are overlain in peach for reference. The BEM-Earth reconstruction poles are derived from the addition of the stage rotations for each geodynamic model run to the 42 Ma Pacific absolute motion pole from Seton et al. (2012). Projected error ellipses are determined from each model's published covariance matrices.

here (62-42 Ma) in the Doubrovine et al. (2012) model, the Hawaii hotspot moves roughly $380 \mathrm{~km}$ to the southeast whereas Louisville is predicted to move about $90 \mathrm{~km}$ in a similar direction. Even though these estimates are model dependent, at least for the Hawaii hotspot there is overwhelming, and converging, observational and model-based evidence that points to a relatively fast southward motion of the Hawaii plume during Emperor chain formation. Our model provides additional evidence for this inference, as we demonstrate that even the relatively major changes in subduction zone geometry and slab-pull and suction forces experienced by the Pacific plate do not predict anything close to the change in Pacific plate motion direction that would be required to produce the HEB (Fig. 7). Our conclusions differ from those of Faccenna et al. (2012), who modelled Pacific plate driving forces by computing slab pull from a combined plate kinematic and half-space lithospheric cooling model, and obtained larger changes in Pacific plate motion direction than we do. Faccenna et al. (2012) use the age of seafloor along the trench to determine lithospheric thickness, and multiply the thickness by a fixed slab length of $700 \mathrm{~km}$ to estimate subducted slab material in the upper mantle. Rather than assuming any particular slab length we use $10 \mathrm{Myr}$ of the convergence history from Seton et al. (2012) combined with associated oceanic palaeo-age grids, from which we obtain age and thickness of subducting lithosphere in 1 mil- lion year time intervals (see Sect. 2 and Appendix B). Our methodology and the resulting non-uniform distribution of mass along subductions zones results in a pulling force significantly different from that of Faccenna et al. (2012) and partially explains the differences in plate motions between their model and ours. Furthermore, their analytical model does not account for slab suction, whereas our model does. The mean velocity magnitudes of our modelled Pacific plate $\left(5-10 \mathrm{~km} \mathrm{Myr}^{-1}\right)$ are in a similar range as those computed by Faccenna et al. (2012); however the directional differences are as large as $30^{\circ}$, likely owing to the differences in model setup as discussed above.

\subsection{Subduction zone topologies driving plate deformation}

Location and the amount of slab material along subduction zones determines the direction and magnitude of plate motion. Tectonic plates do not move completely rigidly but are free to deform according to the interaction and relative contribution of the slab-pull force, induced suction forces, and basal drag forces over the entire plate. In our models, magnitudes for the second deviatoric stress-invariant values are derived from the change in length of the plate panels and the interval of time steps that the model is run for. The higher a given second deviatoric stress-invariant value, the more likely the plate will yield at that location; however, in reality it is also dependent on the rheological properties of the lithosphere.

At $62 \mathrm{Ma}$ there is an absence of any major subduction zones driving Pacific plate motion and deformation. For this modelled time, significant deformation is due to nearby slabs (Kula, Izanagi, Farallon) being strongly coupled to the plate through slab suction. The flow cell set up by the Izanagi slab is dominant in controlling Pacific plate kinematics at this time, because the trench-perpendicular length of the Izanagi plate is relatively small (Morra et al., 2012). Induced flow in the model results in minimal surface uplift, so radial stress is not apparent. Instead, deformation is caused by induced flow, dragging sections of the plate with spatially varying traction. As a result, deformation due to induced upwellings is minimally constrained.

A major tectonic plate reorganisation between $53-50 \mathrm{Ma}$ has been mapped both in the Southeast Indian Ocean and parts of the Pacific Ocean (Whittaker et al., 2007; Cande and Stegman, 2011), who proposed a link between this event and the subduction of the Pacific-Izanagi ridge (Whittaker et al., 2007). This tectonic reconfiguration is captured between the 62 and $52 \mathrm{Ma}$ models, particularly by a speedup of the Pacific plate. Between these times there is a significant increase in $\sigma_{\mathrm{e}}$ across the entire Pacific plate (Figs. 2 and 3). By $52 \mathrm{Ma}$ the Pacific-Izanagi ridge is fully subducted and the volume of slab material controlling the pull force on the Pacific is at the maximum of all the epochs modelled (Appendix B). The model velocities capture a significant change in absolute 


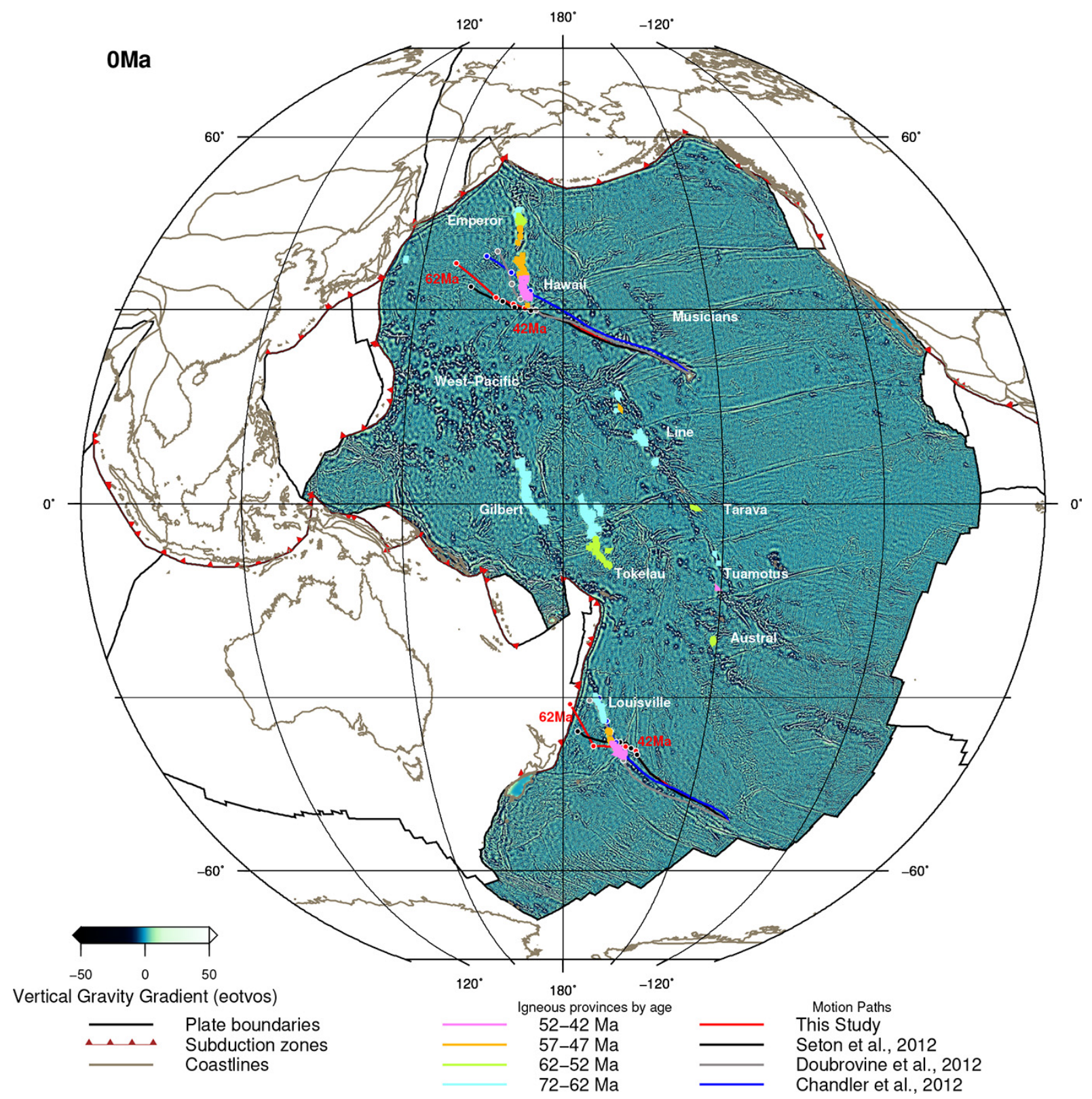

Figure 7. Present-day vertical gravity gradient of the Pacific plate (Sandwell and Smith, 2009). Present-day locations of volcanics dated between 72 and $42 \mathrm{Ma}$ are binned in $10 \mathrm{Myr}$ increments and coloured as in the legend. The computed motion paths for fixed Hawaiian and Louisville hotspots are shown back to $62 \mathrm{Ma}$, for each of the different models, as listed in the legend. Dots along the motion path show the trail's position at $42,47,52$, and 62 Ma respectively.

plate motion during this time interval. The $52 \mathrm{Ma}$ model reflects a peak amplitude in $\sigma_{\mathrm{e}}$ acting to deform the lithosphere over the plate compared to the other modelled times. However, we do not see a marked increase in volcanic flux at this time (Hillier, 2007; Clouard and Bonneville, 2005). This is in contrast to an expected increase in volcanism during such a period of rapid plate motion change (Anderson, 1994; Hieronymus and Bercovici, 2000).

Between 52 and $47 \mathrm{Ma}$ the Junction plate in the western Pacific has fully subducted leaving a smoother plate bound- ary between the Pacific and Philippine plates. In this time period the amount of total global slab material directly pulling the Pacific plate has reduced from $\sim 24 \%$ to $\sim 15 \%$. Changing motions in the Pacific during the Cenozoic have previously been shown to be driven by the variations in slab pull (Faccenna et al., 2012) and slab suction (Conrad and Lithgow-Bertelloni, 2004). And, asymmetric distribution of slab material along the subduction zones partially controls the location of intraplate deformation (Clouard and Gerbault, 2008a). 
The plate topology, subduction zone and slab material configurations driving the 47 and $42 \mathrm{Ma}$ models are relatively similar. In turn, the patterns of deviatoric stress, indicating areas of deformation, across the Pacific plate are similar.

\subsection{Plate deformation correlated with magmatic events and evidence for non-plume-related intraplate volcanism}

A variety of age-dated volcanic structures formed across the Pacific plate between 72 and $42 \mathrm{Ma}$ (Fig. 7), which can be compared with the deformation predicted by our models (Fig. C1). The complexity and abundance of seafloor features are highlighted by the use of the vertical gravity gradient in Fig. 7 - however, seafloor structures that have been sampled and dated to this time period are scarce (Hillier, 2007). Plate stress does not necessarily generate volcanism, just as volcanism can take place without stress and deformation due to subduction, e.g. small-scale convection that is not directly related to deformation. Although plate deformation may induce upwelling and decompression melting, the plate deformation (cracking) can also serve to simply facilitate the rise of melts that already exist or are produced by other mechanisms.

The northernmost area of Pacific intraplate volcanism in Fig. 7 contains the Emperor seamounts (Duncan and Keller, 2004), a product of plume-plate interaction (Sharp and Clague, 2006). However, throughout its formation history, subduction-driven plate stress (inferring deformation) is seen to overlap with the chain. A region of high $\sigma_{\mathrm{e}}$, between 15$30^{\circ} \mathrm{N}$, encompasses the southern part of the Emperor chain in the $52 \mathrm{Ma}$ model run (Fig. 3). Rather than produce new volcanism, deformation induced during the $52 \mathrm{Ma}$ time period may impose small stress-bends in the pre-existing linear chain (Koppers and Staudigel, 2005). The $47 \mathrm{Ma}$ model (Fig. 4) continues to show plate stress, with a diminished magnitude, overlapping with the Hawaiian-Emperor chain. Volcanism is active during the $42 \mathrm{Ma}$ model time period in Hawaii (Sharp and Clague, 2006) and the chain continues to show age-progressive volcanism after the bend at $47 \mathrm{Ma}$. But the $42 \mathrm{Ma}$ model shows minimal plate stress correlated with the location of the chain.

In the north-east of the Pacific plate lies the Musicians volcanic ridges, that have active volcanism prior to our model run epochs. They formed from a hotspot interacting with a spreading ridge between 96 to $75 \mathrm{Ma}$ (Pringle, 1993; Kopp et al., 2003). In the 62 and 52 Ma models in the Musicians seamounts there is increased second deviatoric stress invariant indicated by the model (Fig. 3). The 47 and 42 Ma models continue to show increased $\sigma_{\mathrm{e}}$ around the Musicians ridge. The coincidence of stress with the extinct ridge may incite late-stage volcanism in the province.

The Louisville seamount chain in the South Pacific documents a history of volcanism from 82 to $42 \mathrm{Ma}$ (Koppers et al., 2010, 2011), associated with classical hotspot activity
(Koppers et al., 2004). There is stressed lithosphere toward the north of the chain in the $42 \mathrm{Ma}$ model (Fig. 5). However, deformation resulting from this stress is likely not the main driver of magmatism, but would aid in decompressional melting of the hotspot material.

The Austral seamounts show volcanism between 62 and $52 \mathrm{Ma}$ (Clouard and Bonneville, 2005). This region of seamounts is influenced by many hotspots (Clouard and Bonneville, 2005) and also shows correlation with highly stressed lithosphere at $52 \mathrm{Ma}$ (Fig. 3). This suggests correlation between hotspots located under lithosphere weakened by previous volcanism (Hillier, 2007).

In the western Pacific (Fig. 7) there are several clusters of seamounts that together encompass the Western Pacific Seamount Province. This province shows weak ageprogression in some areas (Ito and van Keken, 2007), suggesting some formation mechanism other than a plume. Koppers et al. (2003) show that there are in fact some age progressions in this region, but overall is a rather complex area with a spike in volcanism lasting until $\sim 70 \mathrm{Ma}$. This province includes the Japanese seamounts (Ozima et al., 1983) in the north, the Mid-Pacific Mountains (Pringle, 1993) that show weak age progression in the central region, and the Magellan seamounts to the south. Between 82 and $62 \mathrm{Ma}$ there are only four Japanese seamounts displaying volcanism, with no mapped features correlating with our modelled plate-stress.

The Line Islands in the central Pacific are considered to have formed through volcanism due to lithospheric extension (Davis et al., 2002). Their temporal appearance between 80 and $68 \mathrm{Ma}$ is not correlated with subduction-driven deformation observed in the $62 \mathrm{Ma}$ model. The Line Islands show reduced volcanism after this time until $55 \mathrm{Ma}$ without any deforming regions coinciding with their formation. The lack of coincidence between subduction-driven $\sigma_{\mathrm{e}}$ and Line Islands volcanism suggest that the magmatism is influenced by another process. Lithospheric extension in this region is possibly related to the upwarping of the superswell in the eastern South Pacific (Davis et al., 2002).

The initial formation of the Gilbert Ridge can be extended back in time along the Marshall Islands to around $100 \mathrm{Ma}$ (Konter et al., 2008; Koppers et al., 2003). Basement near the ridge was likely preconditioned to volcanism (Koppers et al., 2007) because of the emplacement of volcanic sills during the formation of the Ontong-Java and Hikurangi plateaus around $125 \mathrm{Ma}$. The location of the Gilbert chain follows a likely zone of weakness extending north from the ManihikiChasca ridge, and running parallel to existing fracture zones (Fig. 2). The Gilbert ridge has been shown to have poor age progression and also shows signs of stress bends at times after formation (Koppers et al., 2007). Volcanism is expressed from 72 to $62 \mathrm{Ma}$ at the Gilbert ridge and later at the TuvaluEllice and Samoan seamount chain (Koppers and Staudigel, 2005). This chain trends in the same northwest direction as the zone of high- $\sigma_{\mathrm{e}}$ banding in the central Pacific seen in 
Fig. 2. The measured strain (change in evolved model length divided by the original length, $\epsilon$ ) in the modelled Pacific plate around the Gilbert ridge reveals the Gilbert chain is on average experiencing tensional deformation also aligned with the orientation of the band of high $\sigma_{\mathrm{e}}$ (Fig. 2). It has been shown that seamount chains are generally aligned with the direction of the most tensile principal tectonic stress (Hieronymus and Bercovici, 2000). The timing of the modelled lithospheric deviatoric stress invariant correlates with the formation age of $67 \mathrm{Ma}$ (Koppers and Staudigel, 2005), with continued stress likely influencing a long slow stress-bend after the Gilbert chain's formation. Stressed Pacific lithosphere overprinting pre-existing weaknesses seems to have been significant enough to activate the Gilbert chain around this time. Melt material may have already existed in the upper mantle from the events around $100 \mathrm{Ma}$, only requiring the changing tectonic stresses, incited by the subducting Izanagi slab, to initiate surface volcanism.

The Tokelau seamounts and Phoenix Islands are formed between 72 and $62 \mathrm{Ma}$ in the eastern Pacific (Koppers and Staudigel, 2005), away from any significant tectonic stresses. The Tokelau seamounts are volcanically active between the 62 and $47 \mathrm{Ma}$ models, correlating with a well-defined region of high $\sigma_{\mathrm{e}}$ (Figs. 3-5). Formation of these structures are likely influenced by lithospheric extension (Koppers and Staudigel, 2005) on crust weakened by nearby fracture zones.

The Tarava seamounts become active for the $42 \mathrm{Ma}$ model and are thought to have formed from a hotspot influenced by lithospheric stress and deformation (Clouard et al., 2003). This is consistent with the regionally stressed area overlapping the location of the reconstructed sample location (Fig. 5). An unknown source mechanism has produced volcanic activity along the poorly sampled and dated nearby Tuamotus seamounts, around $40-50 \mathrm{Ma}$, visible in the $47 \mathrm{Ma}$ and 42 Ma models (Figs. 4 and 5). There is minimal correlation between modelled plate stress and the formation of these seamounts.

It has previously been shown that present-day subduction zone forces on the Pacific plate lead to internal deformation (Clouard and Gerbault, 2008a, b). Extensional mechanisms and lithospheric thickness variations can contribute to enhanced volcanism on ridges and hotspots, but neither mechanism is likely the sole source of seamount chains (Pilger, 2008). Lithospheric weaknesses (e.g. fracture zones, preexisting magmatism) that override a source of melt material, possibly derived from mantle plumes too weak to penetrate the surface, may be perturbed by tectonic stresses due to plate motion changes, in turn exciting surface eruption. Agedated late Cretaceous and early Cenozoic seafloor structures across the Pacific show signs of Pacific-wide plate deformation. Intraplate volcanism sampled across the Pacific is partially indicative of a proposed global reorganisation (Whittaker et al., 2007; Cande and Stegman, 2011) between about 62 and $47 \mathrm{Ma}$ and may be considered as a proxy for stress on the plate (Clouard and Gerbault, 2008a). Because the stress state of the lithosphere, plate deformation, and subsequent volcanism are inherently mixed, but are not necessarily mutually exclusive, it is difficult to extract a definitive location of volcanism based on stress or deformation alone, or vice versa. This is even more so where there is pre-existing hotspot volcanism in reactivated seamount chains. However, regions likely to deform predicted by our models gives an indication of potential sites of intraplate volcanism that are related to anomalously stressed lithosphere.

\subsection{Modelled lithospheric structure influencing plate deformation}

There is competition between thermal contraction that strengthens the lithosphere during cooling as the lithosphere gets older and thicker (Koppers and Watts, 2010) and loadinduced stress relaxation that weakens it. However, it is found that plate thickness seems to have no noticeable effect on plate deformation, driven by large-scale convection in our models, regardless of the tectonic configuration. This is likely because the plate rheology is homogeneous and there is no heat flow in the model that would otherwise create a weakened crust (Shaw and Lin, 1996). Also the thickness variations are comparatively small to the major convective cells in the model domain.

The rheology of the modelled subducting plate and the mantle will influence the deformation and stress state of the plate. In the models, decreasing the lithosphere viscosity to $50 \times \eta_{\mathrm{m}}$ or increasing it to $200 \times \eta_{\mathrm{m}}$ will make the model evolve slower or faster, respectively. However, regions of deformation remain broadly consistent between models with a different viscosity lithosphere. Intraplate deformation resulting from the stresses imposed by the subduction and mantle drag/suction forces are a robust prediction of the model. Whether the stresses are sufficient to cause intraplate deformation depends on the actual rheological parameters of the Pacific plate. A subsequent increase in deformation may result in volcanism only if melt material is available, and the lithosphere has pre-existing lines of weakness and/or is weak enough to fracture (Ballmer et al., 2009; Hieronymus and Bercovici, 2000).

\subsection{Numerical model limitations summary}

We seek to replicate slab motion driven by buoyancy forces to determine how these forces are stressing the lithosphere. We assume that increased second deviatoric stress invariant in the lithosphere results in a larger likelihood of deformation and potentially leads to intraplate volcanism. Certain model limitations need to be considered when interpreting the results.

The method for building the slab material driving the plates will essentially dictate the amount pulling force (Faccenna et al., 2012; Billen, 2008; Conrad and LithgowBertelloni, 2004, 2002). We assume that a given convergence 
history between a subducting and overriding plate is related to the amount of slab material contributing to the pulling force, so alternate plate motion models used to build the slab and plate topologies would result in different initial model conditions.

Lack of mantle layering will influence the ratio of slabpull and suction force (Morra et al., 2012, 2010; Conrad and Lithgow-Bertelloni, 2004). Our model approach is essentially instantaneous and has an isoviscous mantle, thus implying that our models do not capture potential increases in the mantle's resistance to slab sinking in and below the transition zone. However, it has been shown that viscosity in the transition zone drops due to high water content (Hebert and Montési, 2013), and high resistance to upper mantle slabs may not be expected at these depths. Resistance to slab sinking will increase at some depth below the transition zone, depending on the viscosity profile of the mantle. However, there does not appear to be compelling evidence that such a strong resistance influences plate motions (Conrad and LithgowBertelloni, 2002; Billen, 2010).

Our simplified plate rheology results in broad-scale plate stress. It is expected that intraplate strain is unrealistically high in our model, since we do not use a highly viscous plate core or the plastic effects that play a role in realistic plates. This implies that our modelled deviatoric stress is expected to be more diffuse than localised deformation in nature, and this affects the force balances around the plate. The constitutive relationship of the material that we use for the plate can be regarded as unrealistic, but models of the semi-rigid rheology of the plates as part of a global model has so far only been applied to present-day plate motions (e.g. Stadler et al., 2010), never to sequences of models for the past. We therefore regard our model approach as a reasonable step forward. We use the second deviatoric stress invariant as a measure of "likelihood" for a plate to deform, as the models do not have brittle or plastic yielding. Also, we do not know the actual regional plate rheology (rather we only know the estimated model rheology). We can only infer where there are existing plate weaknesses (not implemented in the models, but discussed qualitatively) and where the value for $\sigma_{\mathrm{e}}$ is high then you are most likely to get plate rupture (expressed through volcanism). Finally, thermal effects that would play a role in deformation are not considered in the model.

We derive plate stage rotations for a given geodynamic model by computing the best-fit Euler pole of the entire motion of the plate derived from the modelled plate motion vectors. As the Pacific is deforming in the model, there would be a spread of Euler poles that describe different areas of the plate's rotation (Alisic et al., 2012). We compare matching plate motions of the deforming modelled plates (not being rigid) and the rigid kinematic reconstructions by calculating stage rotations of the entire Pacific plate for all model times. In this way we aim to characterise which plate motions are compatible with the modelled slab pull and which are not.

\section{Conclusions}

During the Late Cretaceous and early Cenozoic the Pacific plate underwent a major tectonic shift in its primary driving forces; the plate changed from being entirely surrounded by mid-ocean ridges to a topology characterised by a progressive increase in subduction zones particularly along its western and northern perimeter. In our models prior to $52 \mathrm{Ma}$, the Pacific was controlled by the Izanagi, Kula and Farallon subducting plates surrounding it, and to a lesser extent by a small subducting slab attached at the East Junction subduction zone. From $52 \mathrm{Ma}$ onwards, following the subduction of the Pacific-Izanagi ridge, the Pacific plate was primarily controlled by slab pull in the northwest. The absolute motions of the Pacific derived from subduction-driven forces correspond well with other modelled plate reconstructions (Seton et al., 2012; Chandler et al., 2012), when model assumptions and simplifications are taken into account. Slab pull and suction combined control the deformation in the attached subducting plate. We find that the regions of highest second deviatoric stress invariant occur directly adjacent to the most voluminous subducting slabs. Several areas of stressed lithosphere across the Pacific can be linked to agedated intraplate volcanism. The seamount chains of HawaiiEmperor, Louisville, and Tokelau are subject to lithospheric deformation occurring during the early Cenozoic. Plate-scale extensional stresses between our modelled time intervals correlate with a large section of the location and timing of formation of the Gilbert chain, suggesting an origin largely due to lithospheric extension at this time. The Musicians volcanic ridges, which likely formed by traditional plume mechanisms, spatially correlate with modelled lithospheric stress and is a likely candidate for late-stage volcanism between 52 and 42 Ma. Our simplified 3-D subduction simulations suggest stress-induced deformation in the Pacific during the late Cretaceous and early Cenozoic is partially controlled by plate-scale kinematics. Our dynamic models, combined with kinematically reconstructed absolute plates motions, confirm the view that the HEB is largely not due to a change in absolute plate motion, but that it mainly reflects the slowdown of the Hawaiian plume drift. 


\section{Appendix A: Comparison of initial model condition with Slab1.0}

We use $10 \mathrm{Myr}$ of subduction history to build the slabs attached to the geodynamic model subducting plates. The kinematics of the plate model (Seton et al., 2012) determines the total volume of material, dip and depth of the slab. We find these dips to be comparable to the available Slab1.0 (Hayes et al., 2012) present-day slabs (Figs. A1-A6).

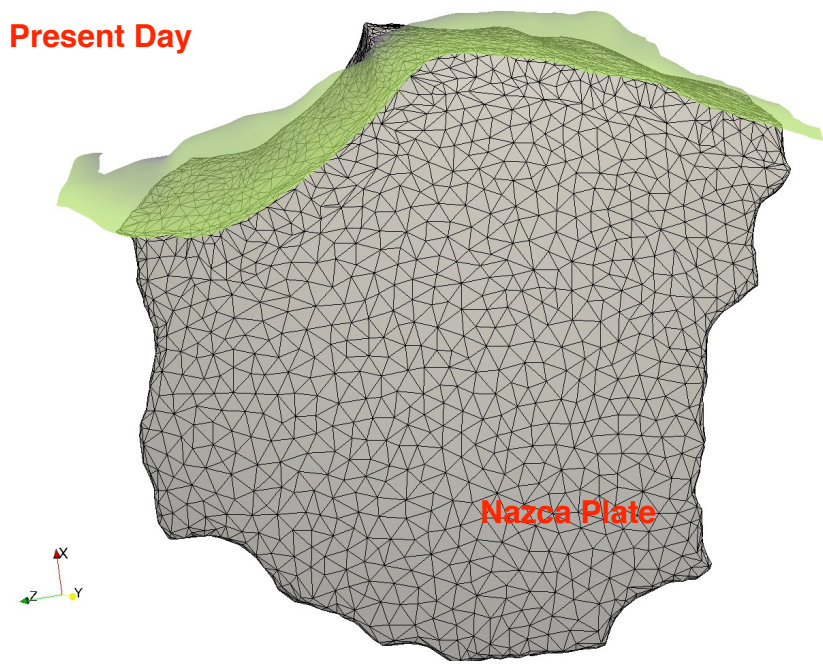

Figure A1. Top-down view of the Nazca plate at present day for geodynamic model input. The green to purple coloured topology represents the depth of the Nazca slab from the Slab1.0 (Hayes et al., 2012) interpretation. The black mesh over the plate indicates the resolution of the model. The Slab1.0 interpretation is made slightly transparent to see the extent of modelled plate.

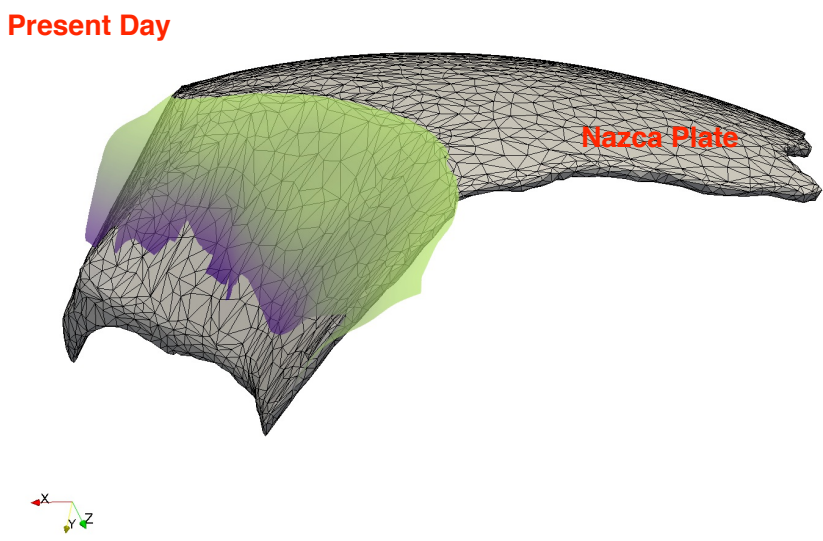

Figure A2. North side view of the Nazca plate at present day for geodynamic model input. The green to purple coloured topology represents the depth of the Nazca slab from the Slab1.0 (Hayes et al., 2012) interpretation. The black mesh over the plate indicates the resolution of the model. The Slab1.0 interpretation is made slightly transparent to see the extent of modelled plate.

\section{Present Day}

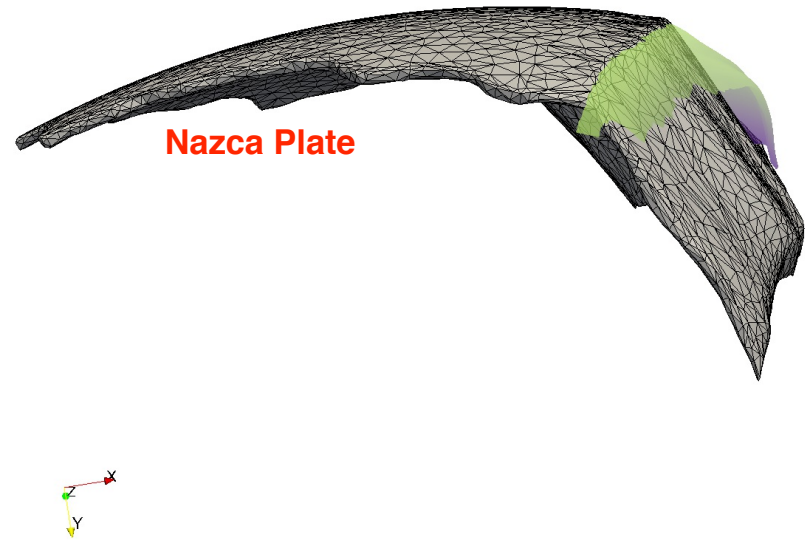

Figure A3. South side view of the Nazca plate at present day for geodynamic model input. The green to purple coloured topology represents the depth of the Nazca slab from the Slab1.0 (Hayes et al., 2012) interpretation. The black mesh over the plate indicates the resolution of the model. The Slab1.0 interpretation is made slightly transparent to see the extent of modelled plate.

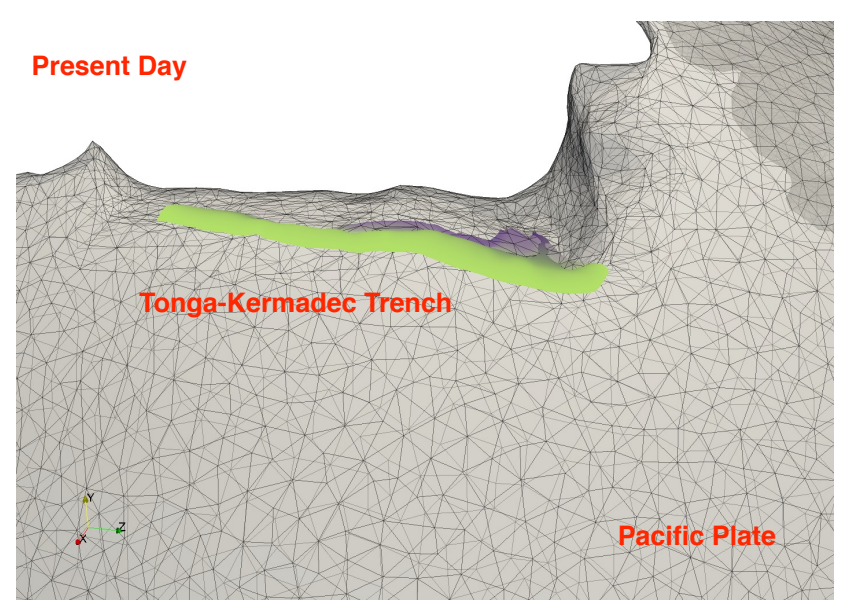

Figure A4. Top-down view of the Pacific plate at present day for geodynamic model input, localised over the Tonga-Kermadec subduction zone. The green to purple coloured topology represents the depth of the Kermadec slab from the Slab1.0 (Hayes et al., 2012) interpretation. The black mesh over the plate indicates the resolution of the model. The modelled plate is made slightly transparent to see the extent of the Slab1.0 interpretation. 


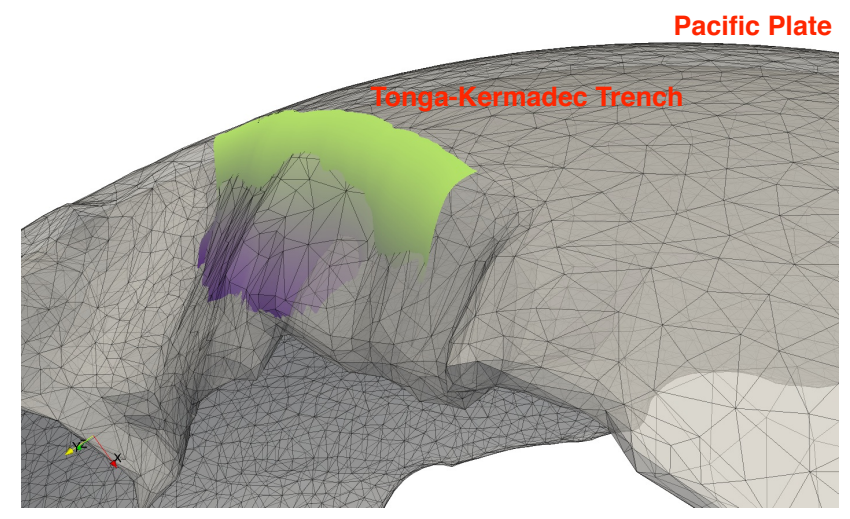

Figure A5. Side view of the Pacific plate at present day for geodynamic model input, looking from the south at the Tonga-Kermadec subduction zone. The green to purple coloured topology represents the depth of the Kermadec slab from the Slab1.0 (Hayes et al., 2012) interpretation. The black mesh over the plate indicates the resolution of the model. The modelled plate is made slightly transparent to see the extent of the Slab1.0 interpretation.

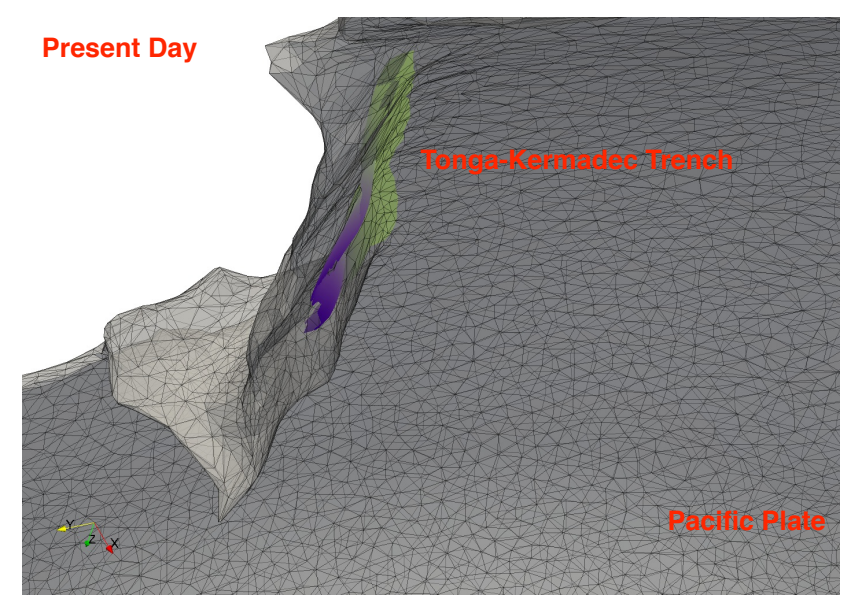

Figure A6. View of the Pacific plate at present day for geodynamic model input, looking from beneath the plate at the Tonga-Kermadec subduction zone. The green to purple coloured topology represents the depth of the Kermadec slab from the Slab1.0 (Hayes et al., 2012) interpretation. The black mesh over the plate indicates the resolution of the model. 


\section{Appendix B: Volume of subducted material}

Plate convergent velocities are determined for each point along the reconstructed subduction zone for each time period. Oceanic lithosphere thickness is derived from the palaeo-reconstruction model (Seton et al., 2012) along with sampling age grids with a $1^{\circ} \times 1^{\circ}$ resolution (Müller et al., 2013). Using a Half-Space Cooling model truncated at $95 \mathrm{~km}$ (after Sect. 4.2 Schubert et al., 2001), the thickness of the lithosphere, $z$, is determined as

$z=\operatorname{erf}^{-1}\left(\frac{T_{1}-T_{\mathrm{o}}}{T_{\mathrm{m}}-T_{\mathrm{o}}}\right) 2 \sqrt{\kappa} \sqrt{\mathrm{age}}$,

where $\operatorname{erf}^{-1}$ is the inverse of the error function, $T_{1}=1300^{\circ} \mathrm{C}$ and is the isotherm of the lithosphere, $T_{\mathrm{o}}=0^{\circ} \mathrm{C}$ and is the surface temperature, $T_{\mathrm{m}}=1600^{\circ} \mathrm{C}$ and is the temperature of the mantle, $\kappa=8 \times 10^{-8} \mathrm{~m} \mathrm{~s}^{-1}$ and is the thermal diffusivity constant, and age is the age of the lithosphere sampled from the age grids. We calculate the volume of the slab as the convergence rate times the lithospheric thickness times each subduction segment length (from the resolution of the plate model). Figures B1-B4 show the amount of globally subducted material for each of the model time periods.

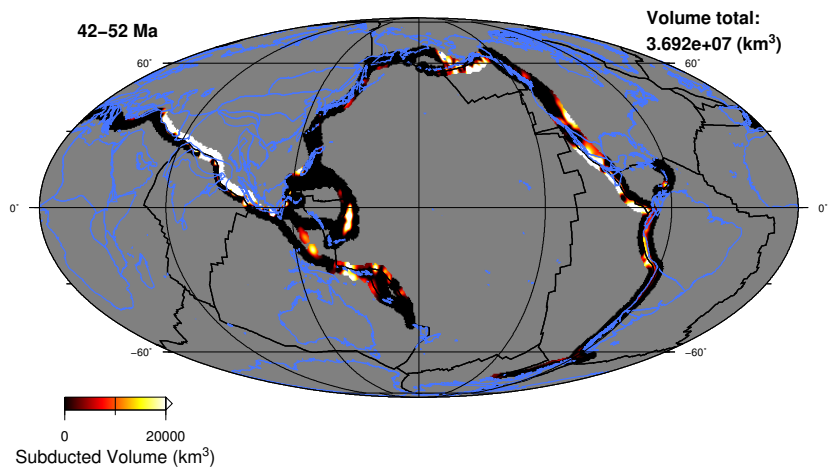

Figure B1. Integrated volume of subducted material between 52 and $42 \mathrm{Ma}$. The colour scale represents the volume of material. The total amount of material for this time period is $3.7 \times 10^{7} \mathrm{~km}^{3}$.

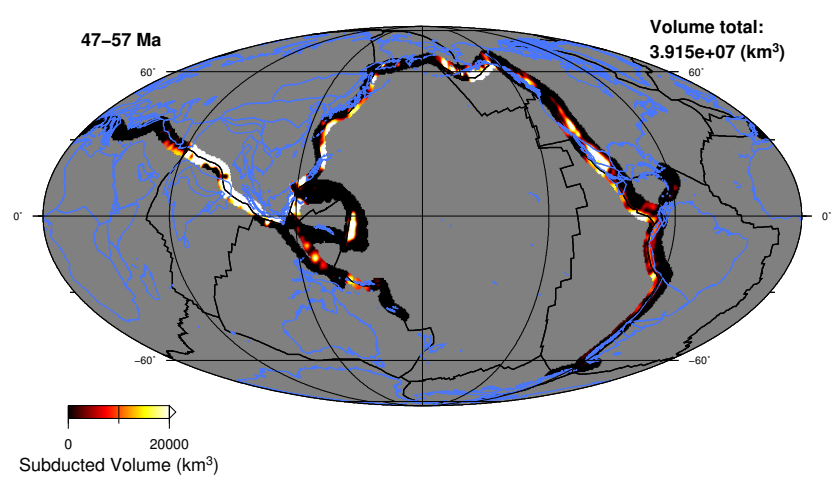

Figure B2. Integrated volume of subducted material between 57 and $47 \mathrm{Ma}$. The colour scale represents the volume of material. The total amount of material for this time period is $3.9 \times 10^{7} \mathrm{~km}^{3}$.

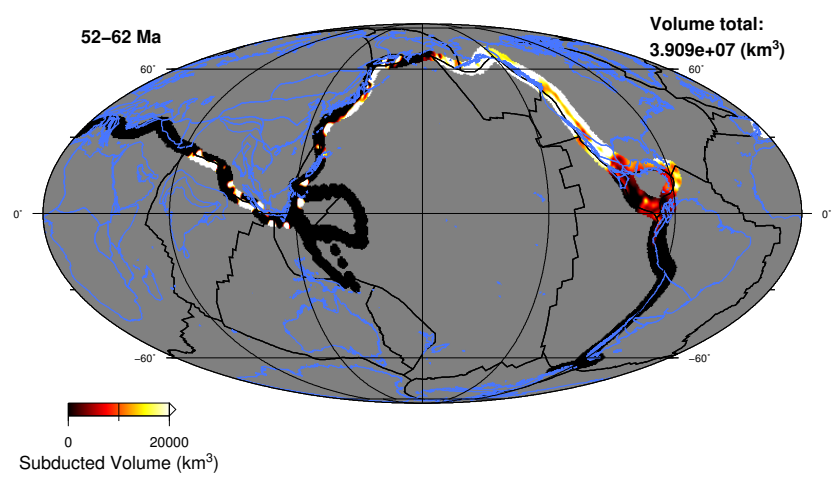

Figure B3. Integrated volume of subducted material between 62 and $52 \mathrm{Ma}$. The colour scale represents the volume of material. The total amount of material for this time period is $3.9 \times 10^{7} \mathrm{~km}^{3}$.

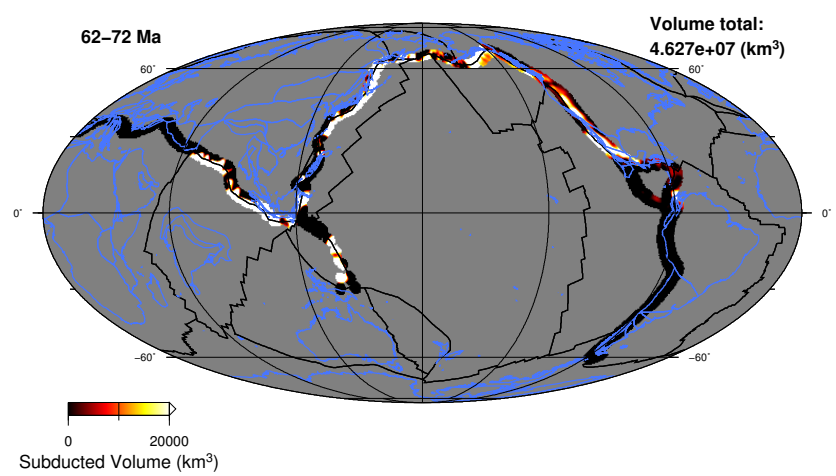

Figure B4. Integrated volume of subducted material between 72 and $62 \mathrm{Ma}$. The colour scale represents the volume of material. The total amount of material for this time period is $4.6 \times 10^{7} \mathrm{~km}^{3}$. 


\section{Appendix C: Second deviatoric stress invariant through time}

For each point of volcanism from Fig 7 we determine the upper 95th percentile of second deviatoric stress invariant occurring within a 1 degree radius around the point at the time of volcanism (Fig. C1). The reconstructed position of the volcanic structures and the diffuse location of the deviatoric stress contribute to the spatial error between the data sets.

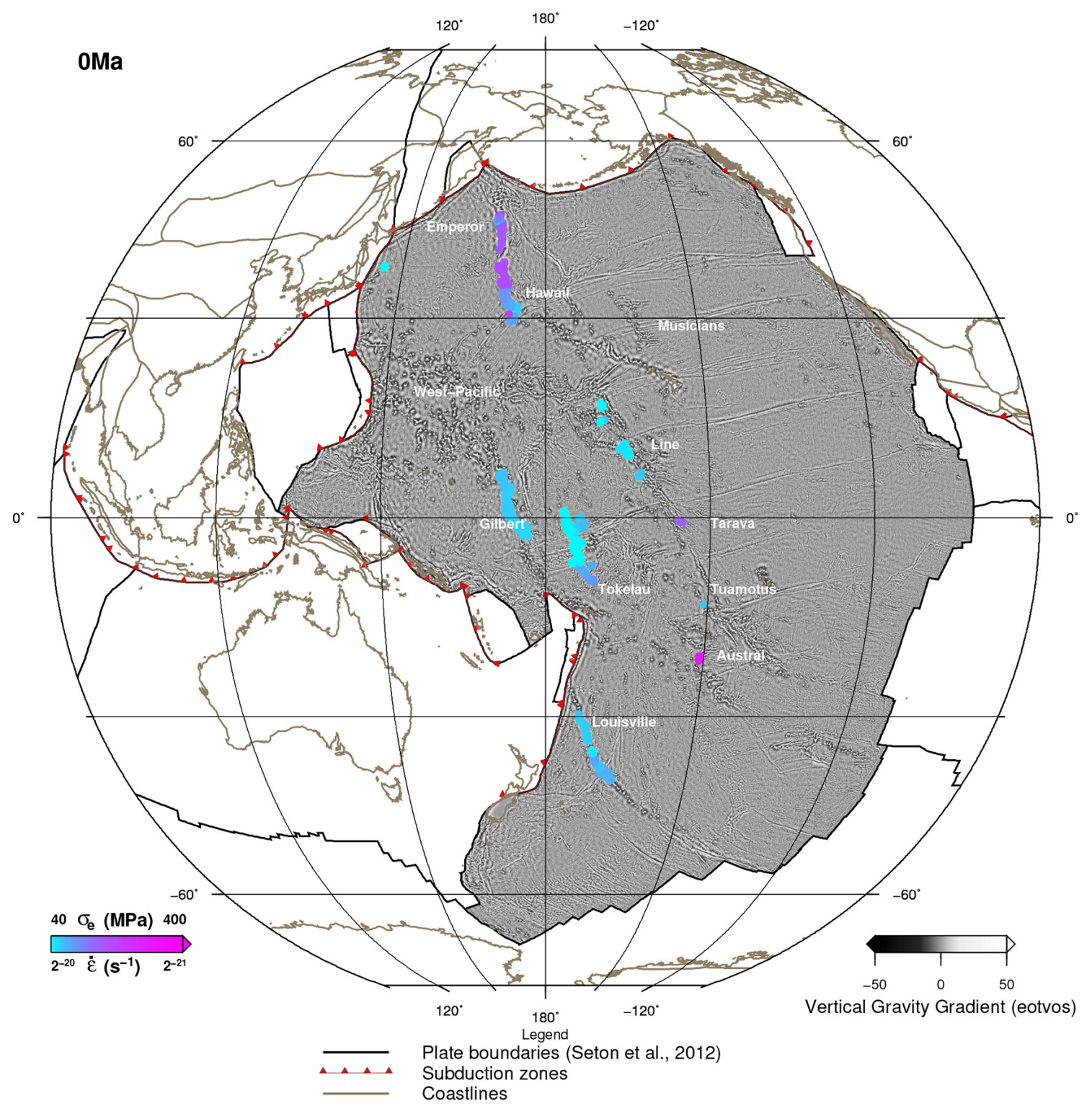

Figure C1. Second deviatoric stress invariant $\left(\sigma_{\mathrm{e}}\right)$, along with the strain rate $\left(\dot{\varepsilon}=\sigma_{\mathrm{e}} / 2 \eta_{s}\right)$, as a prediction for areas likely to deform at the time of volcanism for the structures discussed in the text. The deviatoric stresses shown here are the upper 95th percentile of a 1 degree radius around each point of volcanism shown in Figs. 2-5. This is overlain on the vertical gravity gradient highlighting Pacific seafloor structures for reference to Fig. 7. 
Acknowledgements. We thank C. Heine and S. Williams for fruitful discussions, and to A. A. P. Koppers and two anonymous referees for reviewing the paper.

Edited by: T. Gerya

\section{References}

Alisic, L., Stadler, G., Burstedde, C., and Ghattas, O.:Multi-scale dynamics and rheology of mantle flow with plates, J. Geophys. Res., 117, B10402, doi:10.1029/2012JB009234, 2012.

Anderson, D.: Superplumes or supercontinents?, Geology, 22, 39-42, doi:10.1130/0091-7613(1994)022<0039:SOS>2.3.CO;2, 1994.

Ballmer, M., van Hunen, J., Ito, G., Bianco, T., and Tackley, P.: Intraplate volcanism with complex age-distance patterns: a case for small-scale sublithospheric convection, Geochem. Geophy. Geosy., 10, Q06015, doi:10.1029/2009GC002386, 2009.

Ballmer, M. D., Conrad, C. P., Smith, E. I., and Harmon, N.: Nonhotspot volcano chains produced by migration of shear-driven upwelling toward the East Pacific Rise, Geology, 41, 479-482, doi:10.1130/G33804.1, 2013.

Billen, M.: Modeling the dynamics of subducting slabs, Annu. Rev. Earth Pl. Sc., 36, 325-56, doi:10.1146/annurev.earth.36.031207.124129, 2008.

Billen, M.: Slab dynamics in the transition zone, Phys. Earth Planet. Int., 183, 296-308, doi:10.1016/j.pepi.2010.05.005, 2010.

Bonatti, E.: Not so hot "hot spots" in the oceanic mantle, Science, 250, 107-111, doi:10.1126/science.250.4977.107, 1990.

Boresi, A. P. and Schmidt, R. J.: Advanced Mechanics of Materials, John Wiley and Sons, 2003.

Boyden, J., Müller, R., Gurnis, M., Torsvik, T., Clark, J., Turner, M., Ivey-Law, H., Watson, R., and Cannon, J.: Next-generation platetectonic reconstructions using GPlates, in: Geoinformatics: Cyberinfrastructure for the Solid Earth Sciences, edited by: Keller, G. R. and Baru, C., Chap. 7, Cambridge University Press, 95116, doi:10.1017/CBO9780511976308.008, 2011.

Burkett, E. R. and Billen, M. I.: Dynamics and implications of slab detachment due to ridge-trench collision, J. Geophys. Res.-Sol. Ea., 114, B12402, doi:10.1029/2009JB006402, 2009.

Butterworth, N., Quevedo, L., Morra, G., and Müller, R.: Influence of overriding plate geometry and rheology on subduction, Geochem. Geophy. Geosy., 13, Q06W15, doi:10.1029/2011GC003968, 2012.

Cande, S. C. and Stegman, D. R.: Indian and African plate motions driven by the push force of the Réunion plume head, Nature, 475, 47-52, doi:10.1038/nature10174, 2011.

Capitanio, F., Stegman, D., Moresi, L., and Sharples, W.: Upper plate controls on deep subduction, trench migrations and deformations at convergent margins, Tectonophysics, 483, 80-92, doi:10.1016/j.tecto.2009.08.020, 2010.

Chandler, M. T., Wessel, P., Taylor, B., Seton, M., Kim, S.S., and Hyeong, K.: Reconstructing Ontong Java Nui: implications for Pacific absolute plate motion, hotspot drift and true polar wander, Earth Planet. Sc. Lett., 331-332, 140-151, doi:10.1016/j.epsl.2012.03.017, 2012.

Clouard, V. and Bonneville, A.: Ages of seamounts, islands, and plateaus on the Pacific plate, Geol. Soc. Am. S., 388, 71-90, doi:10.1130/0-8137-2388-4.71, 2005.
Clouard, V. and Gerbault, M.: Break-up spots: Could the Pacific open as a consequence of plate kinematics?, Earth Planet. Sc. Lett., 265, 195-208, doi:10.1016/j.epsl.2007.10.013, 2008a.

Clouard, V. and Gerbault, M.: Reply to "Break-up spots: Could the Pacific open as a consequence of plate kinematics?" Comment by R. Pilger, Earth Planet. Sc. Lett., 275, 196-199, doi:10.1016/j.eps1.2008.08.008, 2008b.

Clouard, V., Bonneville, A., and Gillot, P.-Y.: The Tarava Seamounts: a newly characterized hotspot chain on the South Pacific Superswell, Earth Planet. Sc. Lett., 207, 117-130, doi:10.1016/S0012-821X(02)01143-3, 2003.

Conrad, C. and Lithgow-Bertelloni, C.: How mantle slabs drive plate tectonics, Science, 298, 207, doi:10.1126/science.1074161, 2002.

Conrad, C. and Lithgow-Bertelloni, C.: The temporal evolution of plate driving forces: importance of "slab suction" versus "slab pull" during the Cenozoic, J. Geophys. Res., 109, B10407, doi:10.1029/2004JB002991, 2004.

Conrad, C. P., Bianco, T. A., Smith, E. I., and Wessel, P.: Patterns of intraplate volcanism controlled by asthenospheric shear, Nat. Geosci., 4, 317-321, doi:10.1038/ngeo1111, 2011.

Courtillot, V., Davaille, A., Besse, J., and Stock, J.: Three distinct types of hotspots in the Earth's mantle, Earth Planet. Sc. Lett., 205, 295-308, doi:10.1016/S0012-821X(02)01048-8, 2003.

Davis, A. S., Gray, L. B., Clague, D. A., and Hein, J. R.: The Line Islands revisited: new ${ }^{40} \mathrm{Ar} /{ }^{39} \mathrm{Ar}$ geochronologic evidence for episodes of volcanism due to lithospheric extension, Geochem. Geophy. Geosy., 3, 1018, doi:10.1029/2001GC000190, 2002.

Doubrovine, P., Steinberger, B., and Torsvik, T.: Absolute plate motions in a reference frame defined by moving hot spots in the $\mathrm{Pa}$ cific, Atlantic, and Indian oceans, J. Geophys. Res., 117, B09101, doi:10.1029/2011JB009072, 2012.

Duncan, R. A. and Keller, R. A.: Radiometric ages for basement rocks from the Emperor Seamounts, ODP Leg 197, Geochem. Geophy. Geosy., 5, Q08L03, doi:10.1029/2004GC000704, 2004.

Faccenna, C., Becker, T. W., Lallemand, S., and Steinberger, B.: On the role of slab pull in the Cenozoic motion of the Pacific plate, Geophys. Res. Lett., 39, L03305, doi:10.1029/2011GL050155, 2012.

Finn, C. A., Müller, R. D. and Panter, K. S.: A Cenozoic diffuse alkaline magmatic province (DAMP) in the southwest Pacific without rift or plume origin, Geochem. Geophy. Geosy., 6, Q02005, doi:10.1029/2004GC000723, 2005.

Goudarzi, M. A., Cocard, M. and Santerre, R.: EPC: Matlab software to estimate Euler pole parameters, GPS Solutions, 18, 153162, doi:10.1007/s10291-013-0354-4, 2014.

Gueydan, F., Morency, C., and Brun, J.-P.: Continental rifting as a function of lithosphere mantle strength, Tectonophysics, 460, 83-93, doi:10.1016/j.tecto.2008.08.012, 2008.

Hayes, G. P., Wald, D. J., and Johnson, R. L.: Slab1.0: a three-dimensional model of global subduction zone geometries, J. Geophys. Res.-Sol. Ea., 117, B01302, doi:10.1029/2011JB008524, 2012.

Hebert, L. B. and Montési, L. G. J.: Hydration adjacent to a deeply subducting slab: The roles of nominally anhydrous minerals and migrating fluids, J. Geophys. Res., 118, 5753-5770, doi:10.1002/2013JB010497, 2013.

Hieronymus, C. and Bercovici, D.: Non-hotspot formation of volcanic chains: control of tectonic and flexural stresses 
on magma transport, Earth Planet. Sc. Lett., 181, 539-554, doi:10.1016/S0012-821X(00)00227-2, 2000.

Hillier, J.: Pacific seamount volcanism in space and time, Geophys. J. Int., 168, 877-889, doi:10.1111/j.1365-246X.2006.03250.x, 2007.

Hirano, N., Takahashi, E., Yamamoto, J., Abe, N., Ingle, S. P., Kaneoka, I., Hirata, T., Kimura, J.-I., Ishii, T., Ogawa, Y., Machida, S., and Suyehiro, K.: Volcanism in response to plate flexure, Science, 213, 1426-1428, doi:10.1126/science.1128235, 2006.

Ito, G. and van Keken, P. E.: Hotspots and melting anomalies, in: Treatise on Geophysics, edited by: Bercovici, D., vol. 7, Mantle Dynamics, Elsevier, 371-435, 2007.

Konter, J. G., Hanan, B. B., Blichert-Toft, J., Koppers, A. A. P., Plank, T., and Staudigel, H.: One hundred million years of mantle geochemical history suggest the retiring of mantle plumes is premature, Earth Planet. Sc. Lett., 275, 285-295, doi:10.1016/j.eps1.2008.08.023, 2008.

Kopp, H., Kopp, C., Morgan, J. P., Flueh, E. R., Weinrebe, W., and Morgan, W.: Fossil hot spot-ridge interaction in the Musicians Seamount Province: geophysical investigations of hot spot volcanism at volcanic elongated ridges, J. Geophys. Res., 108, 2160 , doi:10.1029/2002JB002015, 2003.

Koppers, A. A. P.: Mantle plumes persevere, Nat. Geosci., 4, 816817, doi:10.1038/ngeo1334, 2011.

Koppers, A. A. P. and Staudigel, H.: Asynchronous bends in Pacific seamount trails: a case for extensional volcanism?, Science, 307, 904-907, doi:10.1126/science.1107260, 2005.

Koppers, A. A. P. and Watts, A. B.: Intraplate seamounts as a window into deep Earth processes, Oceanography, 23, 42-57, doi:10.5670/oceanog.2010.61, 2010.

Koppers, A. A. P., Staudigel, H., Pringle, M., and Wijbrans, J.: Short-lived and discontinuous intraplate volcanism in the South Pacific: hot spots or extensional volcanism?, Geochem. Geophy. Geosy., 4, 1089, doi:10.1029/2003GC000533, 2003.

Koppers, A. A. P., Duncan, R., and Steinberger, B.: Implications of a nonlinear ${ }^{40} \mathrm{Ar} /{ }^{39} \mathrm{Ar}$ age progression along the Louisville seamount trail for models of fixed and moving hot spots, Geochem. Geophy. Geosy., 5, Q06L02, doi:10.1029/2003GC000671, 2004.

Koppers, A. A. P., Staudigel, H., Morgan, J. P., and Duncan, R.: Nonlinear ${ }^{40} \mathrm{Ar} /{ }^{39} \mathrm{Ar}$ age systematics along the Gilbert Ridge and Tokelau Seamount Trail and the timing of the Hawaii-Emperor Bend, Geochem. Geophy. Geosy., 8, Q06L13, doi:10.1029/2006GC001489, 2007.

Koppers, A. A. P., Yamazaki, T., and Geldmacher, J.: Louisville Seamount Trail: implications for geodynamic mantle flow models and the geochemical evolution of primary hotspots, IODP Scientific Prospectus, 330, doi:10.2204/iodp.sp.330.2010, 2010.

Koppers, A. A. P., Gowen, M. D., Colwell, L. E., Gee, J. S., Lonsdale, P. F., Mahoney, J. J., and Duncan, R.: New ${ }^{40} \mathrm{Ar} /{ }^{39} \mathrm{Ar}$ age progression for the Louisville hot spot trail and implications for inter-hot spot motion, Geochem. Geophy. Geosy., 12, Q0AM02, doi:10.1029/2011GC003804, 2011.

Lee, C.-T. A. and Grand, S. P.: Intraplate volcanism, Nature, 482, 314-315, doi:10.1038/482314a, 2012.

Li, Z.-H. and Ribe, N. M.: Dynamics of free subduction from 3D boundary element modeling, J. Geophys. Res., 117, B06408, doi:10.1029/2012JB009165, 2012.
Lithgow-Bertelloni, C. and Richards, M.: The dynamics of Cenozoic and Mesozoic plate motions, Rev. Geophys., 36, 27-78, doi:10.1029/97RG02282, 1998.

Liu, L. and Stegman, D. R.: Origin of Columbia River flood basalt controlled by propagating rupture of the Farallon slab, Nature, 482, 386-390, doi:10.1038/nature10749, 2012.

Matthews, K., Müller, R., Wessel, P., and Whittaker, J.: The tectonic fabric of the ocean basins, J. Geophys. Res., 116, B12109, doi:10.1029/2011JB008413, 2011.

Morgan, W.: Convection plumes in the lower mantle, Nature, 230, doi:10.1038/230042a0, 1971.

Morra, G., Chatelain, P., Tackley, P., and Koumoutsakos, P.: Large scale three-dimensional boundary element simulation of subduction, in: Computational Science - ICCS 2007, edited by: Shi, Y., Albada, G., Dongarra, J., and Sloot, P., Lecture Notes in Computer Science, 489, 1122-1129, Springer, Berlin, Heidelberg, 1122-1129, doi:10.1007/978-3-540-72588-6_178, 2007.

Morra, G., Yuen, D.A., Boschi, L., Chatelain, P., Koumoutsakos, P., Tackley, P.J.:The fate of the slabs interacting with a density/viscosity hill in the mid-mantle, Phys. Earth Planet. Int., 180, 271-282, doi:10.1016/j.pepi.2010.04.001, 2010.

Morra, G., Quevedo, L., and Muller, R. D.: Spherical dynamic models of top-down tectonics, Geochem. Geophy. Geosy., 13, 1-66, doi:10.1029/2011GC003843, 2012.

Morra, G., Seton, M., Quevedo, L., and Müller, R. D.: Organization of the tectonic plates in the last $200 \mathrm{Myr}$, Earth Planet. Sc. Lett., 373, 93-101, doi:10.1016/j.eps1.2013.04.020, 2013.

Müller, R., Dutkiewicz, A., Seton, M., and Gaina, C.: Seawater chemistry driven by supercontinent assembly, breakup, and dispersal, Geology, 41, 907-910, doi:10.1130/G34405.1, 2013.

O’Neill, C., Müller, D., and Steinberger, B.: On the uncertainties in hot spot reconstructions and the significance of moving hot spot reference frames, Geochem. Geophy. Geosy., 6, Q04003, doi:10.1029/2004GC000784, 2005.

Ozima, M., Kaneoka, I., Saito, K., Honda, M., Yanagisawa, M., and Takigami, Y.: Summary of geochronological studies of submarine rocks from the western Pacific Ocean, in: Geodynamics of the Western Pacific-Indonesian Region, edited by: Hilde, T. W. C., and Uyeda, S., AGU, vol. 11, 137-142 doi:10.1029/GD011p0137, 1983.

Pilger, R.: Discussion of "Break-up spots: could the Pacific open as a consequence of plate kinematics?" by Clouard and Gerbault, Earth Planet. Sc. Lett., 275, 193-195, doi:10.1016/j.eps1.2008.08.005, 2008.

Pringle, M. S.: Age progressive volcanism in the Musicians seamounts: a test of the hot spot hypothesis for the late Cretaceous Pacific, in: The Mesozoic Pacific: Geology, Tectonics, and Volcanism: A Volume in Memory of Sy Schlanger, Geophys. Monogr. Ser, AGU, Washington DC, 77, 187-216, doi:10.1029/GM077p0187, 1993.

Quevedo, L., Hansra, B., Morra, G., Butterworth, N., and Müller, R. D.: Oblique mid ocean ridge subduction modelling with the parallel fast multipole boundary element method, Comput. Mech., 51, 455-463, doi:10.1007/s00466-012-0751-5, 2012 a.

Quevedo, L., Morra, G., and Müller, R. D.: Global paleolithospheric models for geodynamical analysis of plate reconstructions, Phys. Earth Planet. Int., 212-213, 106-113, doi:10.1016/j.pepi.2012.09.007, 2012b. 
Ribe, N. M.: Bending mechanics and mode selection in free subduction: a thin-sheet analysis, Geophys. J. Int., 180, 559-576, doi:10.1111/j.1365-246X.2009.04460.x, 2010.

Ricard, Y., Richards, M., Lithgow-Bertelloni, C., and Le Stunff, Y.: A geodynamic model of mantle density heterogeneity, J. Geophys. Res.-Sol. Ea., 98, 21895-21909, doi:10.1029/93JB02216, 1993.

Romanowicz, B. and Gung, Y.: Superplumes from the core-mantle boundary to the lithosphere: implications for heat flux, Science, 296, 513-516, doi:10.1126/science.1069404, 2002.

Sandwell, D. and Fialko, Y.: Warping and cracking of the Pacific plate Warping and cracking of the Pacific plate by thermal contraction, J. Geophys. Res., 109, B10411, doi:10.1029/2004JB003091, 2004.

Sandwell, D. and Smith, W. H. F.: Global marine gravity from retracked Geosat and ERS-1 altimetry: ridge segmentation versus spreading rate, J. Geophys. Res., 114, B01411, doi:10.1029/2008JB006008, 2009.

Sandwell, D., Winterer, E., Mammerickx, J., Duncan, R., Lynch, M., Levitt, D., and Johnson, C.: Evidence for diffuse exension of the Pacific plate from Pukapuka ridges and crossgrain gravity lineations, J. Geophys. Res., 100, 15087-15099, doi:10.1029/95JB00156, 1995.

Schellart, W.: Quantifying the net slab pull force as a driving mechanism for plate tectonics, Geophys. Res. Lett., 31, L07611, doi:10.1029/2004GL019528, 2004.

Schubert, G., Turcotte, D. L., and Olson, P.: Mantle Convection in the Earth and Planets, Cambridge University Press, 2001.

Seton, M. and Müller, R.: Reconstructing the junction between Panthalassa and Tethys since the Early Cretaceous, Eastern Australian Basins III, Petroleum Exploration Society of Australia, Special Publication, 263-266, 2008.

Seton, M., Müller, R., Zahirovic, S., Gaina, C., Torsvik, T., Shephard, G., Talsma, A., Gurnis, M., Turner, M., Maus, S., and Chandler, M.: Global continental and ocean basin reconstructions since $200 \mathrm{Ma}$, Earth-Sci. Rev., 113, 212-270, doi:10.1016/j.earscirev.2012.03.002, 2012.
Sharp, W. and Clague, D.: 50-Ma initiation of Hawaiian-Emperor bend records major change in Pacific plate motion, Science, 313, 1281, doi:10.1126/science.1128489, 2006.

Shaw, W. J. and Lin, J.: Models of ocean ridge lithospheric deformation: dependence on crustal thickness, spreading rate, and segmentation, J. Geophys. Res., 101, 17977-17993, doi:10.1029/96JB00949, 1996.

Stadler, G., Gurnis, M., Burstedde, C., Wilcox, L.C., Alisic, L. and Ghattas, O.: The dynamics of plate tectonics and mantle flow: From local to global scales, Science, 329, 1033, doi:10.1126/science.1191223, 2010.

Staudigel, H., Park, K.-H., Pringle, M., Rubenstone, J., Smith, W., and Zindler, A.: The longevity of the South Pacific isotopic and thermal anomaly, Earth Planet. Sc. Lett., 102, 24-44, doi:10.1016/0012-821X(91)90015-A, 1991.

Stegman, D., Farrington, R., Capitanio, F., and Schellart, W.: A regime diagram for subduction styles from 3-D numerical models of free subduction, Tectonophysics, 483, 29-45, doi:10.1016/j.tecto.2009.08.041, 2010.

Tarduno, J., Bunge, H.-P., Sleep, N., and Hansen, U.: The Bent Hawaiian-Emperor hotspot track: inheriting the mantle wind, Science, 324, 50-53, doi:10.1126/science.1161256, 2009.

Tarduno, J. A.: On the motion of Hawaii and other mantle plumes, Chem. Geol., 241, 234-247, doi:10.1016/j.chemgeo.2007.01.021, the Great Plume Debate: Testing the Plume Theory, 2007.

Wessel, P. and Kroenke, L. W.: Pacific absolute plate motion since $145 \mathrm{Ma}$ : an assessment of the fixed hot spot hypothesis, J. Geophys. Res., 113, B06101, doi:10.1029/2007JB005499, 2008.

Whittaker, J. M., Muller, R. D., Leitchenkov, G., Stagg, H., Sdrolias, M., Gaina, C., and Goncharov, A.: Major AustralianAntarctic plate reorganization at Hawaiian-Emperor Bend Time, Science, 318, 83-86, doi:10.1126/science.1143769, 2007.

Wilson, J.: A possible origin of the Hawaiian Islands, Can. J. Phys. 41, 863-870, doi:10.1139/p63-094, 1963. 